\title{
Influence of Nickel on High-Temperature Oxidation and Characteristics of Oxide Layers in Two High-Strength Steels
}

Ali Vedaei-Sabegh, Jean-Benoît Morin, and Mohammad Jahazi*

\author{
A. Vedaei-Sabegh, Prof. M. Jahazi \\ Department of Mechanical Engineering \\ École de Technologie Supérieure \\ 1100 Notre-Dame Street West, Montreal, QC H3C 1K3, Canada \\ E-mail: mohammad.jahazi@etsmtl.ca \\ J.-B. Morin \\ Department of Metallurgy \\ Finkl Steel Inc. \\ 100 McCarthy, Saint-Joseph-de-Sorel, QC J3R 3M8, Canada \\ iD The ORCID identification number(s) for the author(s) of this article \\ can be found under https://doi.org/10.1002/srin.201900536.
}

DOI: 10.1002/srin.201900536 


\title{
Influence of nickel on high temperature oxidation and characteristics of oxide layers in two high strength steels
}

\author{
Ali Vedaei-Sabegh ${ }^{1}$, Jean-Benoît Morin ${ }^{2}$, Mohammad Jahazi $^{1 *}$ \\ ${ }^{1}$ École de Technologie Supérieure, Department of Mechanical Engineering, 1100 Notre- \\ Dame Street West, Montreal, QC, H3C 1K3, Canada. \\ ${ }^{2}$ Finkl Steel Inc., 100 McCarthy, Saint-Joseph-de-Sorel, QC, J3R 3M8, Canada \\ * Corresponding author
}

\begin{abstract}
The oxidation behaviors of two high strength medium carbon steels with different $\mathrm{Ni}$ concentrations were investigated by means of differential thermal analysis equipped with thermogravimetry. Four different oxidation temperatures, and five oxidation times were tested. A parabolic behavior was observed for the oxide growth in both alloys; however, the relative increases in the oxidation rate from one temperature to another were not similar for both alloys and the oxidation kinetics of the $\mathrm{Ni}$ rich steel were significantly lower than those of the low $\mathrm{Ni}$ alloy. On the basis of the thermogravimetry results, the activation energy for the oxidation of the two alloys were determined. The influence of $\mathrm{Ni}$ content on the microstructure and characteristics of the different oxide layers was studied using a combination of laser confocal microscopy, electron microscopy and X-ray diffraction (XRD) analysis. The results revealed a clear influence of $\mathrm{Ni}$ on the nature and relative presence of different oxide layers. The results are interpreted in terms of the influence of $\mathrm{Ni}$ on the diffusion of oxygen through the oxide layer.
\end{abstract}

Keywords: High temperature oxidation, Oxidation kinetics, XRD analysis, EDS analysis 


\section{Introduction}

High temperature oxidation during heat treatment or forming operations is an inevitable phenomenon for the majority of steels. Thermally grown oxides on substrates cause material waste and surface damage that could significantly affect surface quality and integrity, resulting in reduced service properties of the component. ${ }^{[1]}$ During hot forming operations, such as forging of large size ingots, thermally grown oxides detach and can indent the material and cause large size cracks which could even result in scrapping of the part. The oxide layer also causes premature tool wear by affecting the friction and heat transfer between the forged ingot and the die. However, the significance of the above defects varies with minor variations in the alloy composition or process parameters. Hence it is important to quantify the influence of changes in chemical composition as well as process parameters on the kinetics of oxide growth and develop a better understanding of the underlying mechanisms. ${ }^{[1-3]}$

Oxidation in carbon steels initiates by discrete nuclei, which expand laterally to join adjacent oxides. When these nuclei reach each other, the oxidation proceeds by mass transfer of ions in a direction normal to the surface. ${ }^{[4]}$ The growth of scale depends on diffusion of cations $\left(\mathrm{Fe}^{2+}\right.$ and $\mathrm{Fe}^{3+}$ ) or anions $\left(\mathrm{O}_{2}^{-}\right)$. In this regard, during the oxidation process, the $\mathrm{Fe}$ cations diffuse outward through the oxide and reach to its top surface, where in contact with the air, the chemical equilibrium is established at the interfaces of gas-oxide and oxide-metal. Diffusion of Fe cations in steel oxide is faster compared to that of oxygen. ${ }^{[5-7]}$ Hence, the diffusivity of Fe in oxide and concentration of vacancies determines the kinetics of oxide growth. Temperature and time are two determinative factors that could increase the diffusivity of Fe and consequently the growth rate of oxide layers. ${ }^{[4,6,8]}$ 
Generally, the oxide crust of pure iron comprises of three layers: Wustite $(\mathrm{FeO})$, the closest layer to the base metal, an intermediate layer, magnetite $\left(\mathrm{Fe}_{3} \mathrm{O}_{4}\right)$, followed by hematite $\left(\mathrm{Fe}_{2} \mathrm{O}_{3}\right)$ layer at the outermost. In general, the thickness ratios of these layers are reported to be $95: 4: 1$ for wustite, magnetite and hematite, respectively. ${ }^{[5,9]}$ Considering the phase ratio of wustite to other layers, it could be concluded that Fe has higher diffusivity in the wustite, ${ }^{[5,9]}$ whose composition has been described as $\mathrm{Fe}_{1-\mathrm{XO}} \mathrm{O}$, where $\mathrm{X}$ could be in the range of 0.04 to 0.17 . Wustite is known to have low hardness and acts as lubricant at high temperature. In contrast, magnetite shows higher hardness, whereas hematite causes severe wear on contacting surfaces by its high hardness. These characteristics could vary with respect to chemical composition of the base metal, oxidizing atmosphere, pressure, temperature and time. ${ }^{[9,10]}$ Chen and Yuen reported that, ${ }^{[1]}$ the growth rate of oxide layer during isothermal heat treatment of a mild steel and pure iron, showed a parabolic behaviour with respect to the oxidation time for temperature range of 700 to $1100{ }^{\circ} \mathrm{C}$ in different atmospheres including oxygen and air. Liu et al. ${ }^{[12]}$ reported that increasing oxidation temperature and time increased the thickness fraction of wustite and decreased that of magnetite, but had negligible effect on hematite for micro-alloyed steel in temperature range of 900 to $1200{ }^{\circ} \mathrm{C}$ in mixture gases of $\left(80 \% \mathrm{~N}_{2}-15 \% \mathrm{CO}_{2}-5 \% \mathrm{O}_{2}\right)$ to simulate the reheat furnace. It has been reported that for pure iron, the initial oxidation rate in short times is determined by the chemical reactions between oxygen atoms at the surface of the metal and adsorbed oxidizing species ${ }^{[8]}$ On the other hand, the diffusion of ionic species, such as oxygen, throughout the oxide layers is the rate controlling factor for the above phases. ${ }^{[8,13]}$

While it has been reported that the growth rate of hematite depends on oxygen diffusion due to the abundance of oxygen close to the surface, that of wustite and magnetite mainly depends on the diffusion of cations, since they are closer to the base metal. ${ }^{[13,14]}$ However, the growth 
mechanism for each of these three layers is still not well documented. ${ }^{[13,15]}$ As each layer demonstrates specific characteristics and tribological behaviours, their distinctive evaluation is essential.

Considering the oxidation kinetics, oxidation atmosphere and chemical composition of the alloy could remarkably affect the oxidation process: Abuluwefa et al. ${ }^{[8,16]}$ reported that the oxidation of a low carbon steel in carbon dioxide and water vapour, in temperature range of 800 to 1150 ${ }^{\circ} \mathrm{C}$, comprised of a single wustite layer; whereas all three layers were present when oxidized in a pure oxygen atmosphere. Yun et al. ${ }^{[17]}$ showed that for oxidation of a low carbon steel at 500 ${ }^{\circ} \mathrm{C}$, wustite was not detected, whereas wustite was dominant layer for oxidation at $700{ }^{\circ} \mathrm{C}$. Also, Yun et al. ${ }^{[17]}$ acquired higher oxygen rate for oxygen containing water vapor compared to those in dry gases. Carbon is the most important alloying element influencing the oxidation kinetics. ${ }^{[18]}$ It could have an accelerating effect on the oxidation rate or reducing it, ${ }^{[11,19]}$ depending on the oxidation conditions. ${ }^{[20]}$ Krzyzanowski et al. ${ }^{[21]}$ and Von Fraunhofer et al. ${ }^{[22]}$ reported that aluminium $(\mathrm{Al})$ can increase the wustite formation temperature and therefore, increase the oxidation resistance of steel. Rahmel et al. ${ }^{[23]}$ and C. H. kaoreported that the formation of a $\alpha-\mathrm{Al}_{2} \mathrm{O}_{3}$ during the oxidation process provides the high-temperature oxidation resistance. ${ }^{[20]}$ Webler et al. ${ }^{[24]}$ and Asai et al. ${ }^{[25]}$ showed that Si can decrease oxidation and also roughen the oxide-metal interface. Li et al. ${ }^{[26]}$ demonstrated that for oxidation of low carbon steel at $1050{ }^{\circ} \mathrm{C}$ in dry and wet air, adding the $\mathrm{Cr}$ element will significantly decrease the oxidation rate by forming $\mathrm{Cr}_{2} \mathrm{O}_{3}$ and $\mathrm{FeCr}_{2} \mathrm{O}_{4}$ layers. Krzyzanowski et al. ${ }^{[21]}$ and $\mathrm{Kim}$ et al. ${ }^{[27]}$ also found that the contribution of $\mathrm{Cr}$ to oxidation resistance of the steel was less than $\mathrm{Si}$ or $\mathrm{Al}$ at temperature of 500 and $700{ }^{\circ} \mathrm{C}$. Furthermore, Takeda et al. ${ }^{[28]}$ reported the formation of $\mathrm{FeOCr}_{2} \mathrm{O}_{4}$ at the interface of oxide-metal for oxidation of three commercial steels, and found 
that it reduces the scale removability. Asai et al. ${ }^{[25]}$ reported that the addition of nickel (Ni) also reduced the scale removability. Laukka et al. ${ }^{[29]}$ found that above $1225^{\circ} \mathrm{C}$ in an $\mathrm{O}_{2}$ atmosphere, oxide growth increased in presence of boron (B), but reduced by Titanium (Ti) addition.

The activation energy of oxidation can also be affected by alloying elements, oxidation temperature or time. Regarding the activation energy of elements and the contributed effects of elements on activation energy of steels, Young reported values in the order of 230 and 120 $\mathrm{KJ} . \mathrm{mol}^{-1}$ for oxidation of $\mathrm{Co}$ in air at temperature between $800-950{ }^{\circ} \mathrm{C}$ and $950-1150{ }^{\circ} \mathrm{C}$, respectively. ${ }^{[30]}$ In the temperature range of $980-1200{ }^{\circ} \mathrm{C}$, an activation energy of $243 \mathrm{KJ} . \mathrm{mol}^{-1}$ was reported for oxidation of $\mathrm{Cr}$ in air by Young. ${ }^{[30]}$ While the activation energy of wustite in

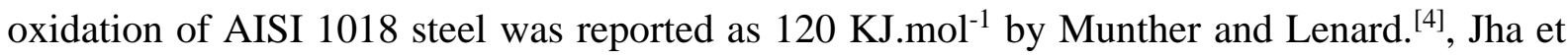
al. ${ }^{[31]}$ reported $178 \mathrm{KJ} \cdot \mathrm{mol}^{-1}$ for $\mathrm{Fe}-19.2 \% \mathrm{Cr}$ steel oxidized at $1000{ }^{\circ} \mathrm{C}$ and related it to the effect of $\mathrm{Cr}$. The same authors calculated an activation energy value of $201 \mathrm{KJ}^{\mathrm{mol}}{ }^{-1}$ for $\mathrm{Fe}-4 \% \mathrm{Si}$ steel in the oxidation temperature range of 800 to $1000{ }^{\circ} \mathrm{C}$ and discussed the significant effect of Si.

In the above studies the specific effect of an element has been investigated; however, the influence of the alloying elements on the characteristics of the different steel oxide layers and the kinetics of oxide growth is still an open question. ${ }^{[3]}$ In the present study, the influence of time and temperature on the kinetics of oxide growth of two medium carbon low alloy steels with differences in Ni content was investigated. The nature, crystallography, microstructural features and evolution of the different oxide layers were characterized as a function of process variables and the role of $\mathrm{Ni}$ in this evolution is quantified. The results are discussed in terms of the interactions of $\mathrm{Ni}$ with other elements and their diffusion through the oxide layer and a mechanism is proposed that accounts for the influence of $\mathrm{Ni}$ on oxidation kinetics and microstructure evolution of oxide layers. 


\section{Materials and methods}

The chemical composition of studied steels is given in Table 1, and identified as low nickel (LNi) and high nickel (HNi). The Ni content in the $\mathrm{HNi}$ is almost 6 times higher compared to the LNi one. Both materials were provided by Finkl steels Sorel, Quebec, Canada.

Oxidation samples were prepared from the cast blocks. For thermogravimetric analysis (TGA) on a PerkinElmer TG/DTA 6300, samples with $4 \mathrm{~mm}$ of diameter and $7 \mathrm{~mm}$ of length were prepared using a precision cutter. Oxidation temperatures of $1000,1100,1150$ and $1200{ }^{\circ} \mathrm{C}$ were chosen, based on the actual working temperatures in industry, to assess the mass gain of samples during 3, 10, 20, 30 and 60 min of exposure time. Samples were placed in the TG/DTA facility on an alumina pan and were heated to the oxidation temperature under $50 \mathrm{ml} . \mathrm{min}^{-1}$ flow of argon to prevent any oxidation before reaching the desired temperature. The samples were heated with the heating rates of $15,14.37,13.75$ and $12.5^{\circ} \mathrm{C} \cdot \mathrm{min}^{-1}$ for oxidation temperatures of $1200,1150,1100$ and $1000{ }^{\circ} \mathrm{C}$, respectively. The different heating rate made the samples reach to the oxidation process at the same heating time to switch the gas from argon to air. At the oxidation temperature, the flowing gas, with the same flow rate, was switched from argon to air by a gas control unit to provide an oxidative environment (Fig. 1). As the chamber is filled with the gas, the sample is in full contact with argon or air. The gas control unit makes the appropriate flow rate of gas to switch it from argon to air in a short time and prevent inaccuracy. The recorded mass gain during this stage, for different oxidation time intervals and temperature, was then utilized for oxidation analysis of the two steels. 
In order to accurately compare the severity of oxidation under different conditions, mass gain by unit surface, $\Delta \mathrm{W} / \mathrm{A}$, was used. Similar approaches have already been used by other authors. ${ }^{[32-34]}$ In the above ratio, $\Delta \mathrm{W}$ represents the mass gain $(\mathrm{g})$ and $\mathrm{A}$ is the surface of sample $\left(\mathrm{cm}^{2}\right)$.

Since the TGA/DTA samples were too small for XRD evaluations and SEM microscopy, another set of samples in the form of rectangular cubes of $10 \times 10 \times 20 \mathrm{~mm}$ were prepared and subjected to the same oxidation temperature and time conditions. The oxidation tests were carried out using a material testing system machine (MTS) equipped with a radiative furnace, ChamberIR E4 elliptical chamber heater, as shown in Fig. 2. This chamber has four elliptical polished aluminium reflectors that focus the supplied infrared energy in the heater centre axis. Samples were heated to the oxidation temperature under argon protection, followed by switching the gas flow to air for desired oxidation time. After the oxidation test, the samples were cooled down to room temperature while reintroducing the protective argon gas in order to avoid possible oxidation during cooling. The furnace temperature was controlled through a PID controller which provided temperature variations of $\pm 3{ }^{\circ} \mathrm{C}$. Temperature measurements were made employing K-type thermocouples. In addition to the furnace thermocouple, two others were placed on opposite faces of the samples to validate that the heating and cooling profiles were identical all around the sample. Prior to oxidation tests, samples were grounded using 320 mesh SiC papers to produce similar surface roughness. All the samples were ultrasonically cleaned for $15 \mathrm{~min}$ in distilled water and ethanol and kept in a vacuum chamber before conducting oxidation tests. 
To evaluate the oxide phases by $\mathrm{XRD}$, the oxide layers were removed from the samples and powdered in a mortar. The powdered oxides were analysed employing a PANalytical X-ray diffractometer with Cobalt $\mathrm{K} \alpha$ radiation, scanned angles from $20^{\circ}$ to $100^{\circ}$, step size of $0.033^{\circ}$, generator voltage of $45 \mathrm{kv}$ and a tube current of $40 \mathrm{~A}$. In order to avoid any peak overlap from the powder holder, a blank test was conducted, which showed no peak superimposition with the oxide ones. Microstructural investigations were conducted using a LEXT OLS4100 laser confocal microscope and a Hitachi SU-8230 Field Emission-STEM equipped with a X-flash EDS quad detector. Special care was taken to protect and conserve the integrity of the oxide layer during sample preparation for microscopic examinations. Specifically, a special cold mounting copper based powder was used to provide high conductivity and minimum manipulation. For this purpose, the oxide layers were preserved in the copper cold mount and then cross sectioned by a diamond blade for microscopic imaging. The mounted samples were grounded to 800 mesh on $\mathrm{SiC}$ papers and were polished on a Buehler vibrometer polisher for 6 hours in a $0.05 \mu \mathrm{m}$ colloidal silica suspension to provide smooth surface finish.

\section{Results and discussion}

3.1 Effect of $\mathrm{Ni}$ on the kinetics of oxide growth

Fig. 3 illustrates the squared mass gain per unit surface for LNi (Fig. 3 a-d) and HNi (Fig. 3 eh) steels. The results indicate that the weight gain of both steels increased with the oxidation temperature or oxidation time. In all cases, for all testing temperatures, oxidation for $3 \mathrm{~min}$ is remarkably less than other oxidation times. The remarkable lower results for this oxidation time could be contributed to the relation of oxidation to square root of time, where there was not sufficient time for diffusion of oxygen. 
For each oxidation temperature, by increasing the oxidation time, the oxidation rate decreases. For instance, by increasing the oxidation time from 10 to $30 \mathrm{~min}$, the squared weight gain per unit surface at $1100{ }^{\circ} \mathrm{C}$ increased from 47.3 to $267.2\left(\mathrm{mg}^{2} \cdot \mathrm{cm}^{-4}\right)$. For the same oxidation temperature, by increasing the oxidation time from 30 to $60 \mathrm{~min}$, the squared weight gain per unit surface increased to $825.9\left(\mathrm{mg}^{2} \cdot \mathrm{cm}^{-4}\right)$, about triple. This phenomenon becomes more significant as the temperature increased to 1150 and $1200{ }^{\circ} \mathrm{C}$. For example, at $1200{ }^{\circ} \mathrm{C}$, the squared weight gain per unit surface increased about $416 \%$ in the oxidation time interval of 10 to $30 \mathrm{~min}$, whereas it only increased by about $115 \%$ in the 30 to 60 min interval. The decreasing tendency of the oxidation rate with time was observed for all studied oxidation temperatures.

The kinetics of oxide growth at the surface of pure iron was studied by Yuan et al. ${ }^{[32]}$ who assessed two approaches for analysing mass gain by unit surface for oxidation in oxygen and steam atmospheres, as follows:

$$
\begin{array}{ll}
\left(\frac{\Delta W}{A}\right)^{2}=k_{p} \cdot t & \text { Parabolic rate kinetics } \\
\left(\frac{\Delta W}{A}\right)=k_{l} \cdot t & \text { Linear rate kinetics }
\end{array}
$$

where $\Delta \mathrm{W} / \mathrm{A}$ is the mass gain per unit area $\left(\mathrm{g} \cdot \mathrm{cm}^{-2}\right), \mathrm{t}$ oxidation time $(\mathrm{s}), \mathrm{k}_{\mathrm{p}}$ the parabolic rate constant $\left(\mathrm{g}^{2} \cdot \mathrm{cm}^{-4} \cdot \mathrm{s}^{-1}\right)$ and $\mathrm{k}_{1}$ is the linear rate constant $\left(\mathrm{g} \cdot \mathrm{cm}^{-2} \cdot \mathrm{s}^{-1}\right)$. The authors found that oxidation of iron in oxygen follows the parabolic kinetics behaviour. The results obtained in the present work are also in agreement with those of Yuan et al. ${ }^{[32]}$, in terms of parabolic oxidation rate pattern. 
The observed behaviour could be related to the fact that solid-state diffusion is the rate controlling factor in the oxidation process. In the initial stages of oxidation, the steel surface is free from oxide layers and therefore the oxide growth would be significantly faster compared to later oxidation times. However, as the oxidation proceeds, the newly formed oxide layers act as barriers to oxygen diffusion and in order to continue the oxidation, oxygen should pass through the oxide layer to reach $\mathrm{Fe}$ (instead of direct contact with $\mathrm{Fe}$ ), which will slow down the oxidation. ${ }^{[35,36]}$ Thus, the increase in the oxide layer thickness after the initial stage will depend on the ease of diffusion for oxygen and Fe through the oxide layers. It is interesting to note that the results for oxidation time intervals of 10 and $20 \mathrm{~min}$ are close, whereas oxidation for 60 min results in significantly thicker oxide layer than other oxidation times.

The faster oxidation rate in the initial stages is in accordance with parabolic growth rate of oxide thickness: $[11,37,38]$

$$
h=\sqrt{k \cdot t}
$$

In the above equation $\mathrm{h}, \mathrm{k}$ and $\mathrm{t}$ are oxide thickness $(\mathrm{cm})$, parabolic growth rate $\left(\mathrm{cm}^{2} \mathrm{~s}^{-1}\right)$, and time (s), respectively. Fig. 3 shows that the oxidation of HNi steel is significantly lower than LNi, under similar conditions. The only different alloying element between the two steels, $\mathrm{Ni}$, is the element which could be the reason for the observed behaviour. On the basis of the results presented in Fig. 3 and equation 4, the activation energy (EA), was determined for the two steels from the slope of the curve ( $\left.\ln \mathrm{k}_{\mathrm{p}} / \mathrm{k}_{0}-1 / \mathrm{RT}\right)$ as reported in Fig. $4:^{[5,30]}$

$$
k_{p}=k_{0} \exp \left(-\frac{E_{A}}{R T}\right)
$$


$\mathrm{k}_{\mathrm{p}}, \mathrm{k}_{0}$ are parabolic oxidation kinetic constants $\left(\mathrm{g}^{2} \cdot \mathrm{cm}^{-4} \cdot \mathrm{s}^{-1}\right), \mathrm{E}_{\mathrm{A}}$ is the activation energy for the oxidation $\left(\mathrm{J} \cdot \mathrm{mol}^{-1}\right), \mathrm{R}$ is the gas constant $\left(8.314 \mathrm{~J} \cdot \mathrm{mol}^{-1} \cdot \mathrm{K}^{-1}\right)$ and $\mathrm{T}$ is the absolute temperature (K). The activation energies for LNi and HNi steels are 238 and $275 \mathrm{~kJ} \cdot \mathrm{mol}^{-1}$, respectively. The higher activation energy value for the HNi steel is indicative of its higher resistance to thermal oxidation.

A comparison between the activation energies obtained in this present study and those reported in the literature (Table 2) shows good agreement with some studies, while significant differences are observed with others. This difference could be attributed to complexity of oxidation by different alloying elements, different oxidation temperature and oxidation environment. ${ }^{[11,39]}$

For example, Chen and Yuen reported activation energy value of about $157 \mathrm{~kJ} \cdot \mathrm{mol}^{-1}$ for oxidation of iron in temperature range $700-1250{ }^{\circ} \mathrm{C} .{ }^{[11]}$ Abuluwefa et al. ${ }^{[8]}$ determined an activation energy value of $127 \pm 7 \mathrm{KJ}_{\mathrm{mol}}{ }^{-1}$ for oxidation of a low carbon steel in temperature range of $1000-1250{ }^{\circ} \mathrm{C}$. In contrast, Yuan et al. ${ }^{[32]}$ using a steel with higher amounts of alloying elements reported an activation energy of $205 \mathrm{KJ}_{\mathrm{mol}}{ }^{-1}$, but their alloy was oxidized at significantly lower temperature of $650-750{ }^{\circ} \mathrm{C}$.

Similarly, Liu et al. ${ }^{[12]}$ obtained an activation energy of $105 \mathrm{KJ} \mathrm{mol}^{-1}$ for a micro-alloyed steel oxidized at $1200{ }^{\circ} \mathrm{C}$, while Munther and Lenard using AISI 1018 steel, which has higher C, but lower amounts of $\mathrm{Ni}, \mathrm{Mn}, \mathrm{Si}, \mathrm{Cr}$ and $\mathrm{Mo}$, reported an activation energy value of $120 \mathrm{KJ} . \mathrm{mol}^{-1}$ at the same temperature. ${ }^{[4]}$ Employing alloying elements at high amounts such as highly alloyed refractory austenitic steels utilized by Madern et al. ${ }^{[40]}$, can show higher activation energy for 
oxidation. Madern et al. ${ }^{[40]}$, acquired $280 \mathrm{KJ} \mathrm{mol}^{-1}$ of activation energy for oxidation at 1000 ${ }^{\circ} \mathrm{C}$.

For oxidation of Ni in air, Young reported the activation energies of 120 and $240 \mathrm{KJ}_{\mathrm{mol}}{ }^{-1}$ at temperature ranges of $600-1100{ }^{\circ} \mathrm{C}$ and $1100-1400{ }^{\circ} \mathrm{C}$, respectively. ${ }^{[30]}$

The above results show a clear influence of $\mathrm{Ni}$ on the kinetics of oxidation and its activation energy; however, the impact of a higher Ni content on the characteristics of the oxide layers is still not well documented. Hence, in the following section the characteristics of oxide layers will be studied.

\subsection{Effect of $\mathrm{Ni}$ on the characteristics of oxide layers}

Fig. 5 provides an illustrative example of the three oxide sub-layers obtained from LNi and $\mathrm{HNi}$ steel samples oxidized at $1000{ }^{\circ} \mathrm{C}$ for 60 min (images obtained using the LEXT OLS4100 laser confocal microscope).

As shown in Fig. 5, the overall thickness of the oxide layer in the LNi steel was in average $14.7 \%$ higher than the one in the HNi steel under similar testing conditions. Specifically, the thickness of the wustite on LNi was $160.2 \mu \mathrm{m}$, while in the HNi it was $139.6 \mu \mathrm{m}$. Similarly, the thicknesses of the magnetite were 85.6 and $74.6 \mu \mathrm{m}$ and those of hematite are 30.4 and 26.5 $\mu \mathrm{m}$ for LNi and HNi steels, respectively. In both steels, the fractions of wustite, magnetite and hematite to overall oxide thickness, are $58 \%, 31 \%$ and $11 \%$, respectively. Hence, despite the reduction of oxidation by higher amounts of $\mathrm{Ni}$, in relative terms the overall fraction of each layer to oxide thickness remained consistent. However, in absolute terms, the lower thickness of oxide layer in the $\mathrm{HNi}$ has resulted in lower, material loss due to oxidation and less die wear 
because of lower amount of hematite. This is in accordance with the study of Barrau et al. ${ }^{[41]}$ on friction and wear tools for forging.

While the cross section of the oxide for LNi steel is porous and rough, that of the HNi is smoother and continuous with few visible porosities as shown in Fig. 5. Furthermore, compared to LNi samples, the oxide - metal interface is rougher in the case of HNi steel, which leads to longer interface. Finally, it must be noted that a thicker transition layer was observed in the HNi steel, which makes additional bond between oxide and metal (see fig. 5). The above phenomena are expected to decrease the scale removability for $\mathrm{HNi}$ and therefore if not properly removed from the surface, oxide could penetrate during forging into the base metal and cause cracking and material waste.

As reported by former studies, the oxide layers are affected by both oxidation time and temperature. ${ }^{[5,9,42]}$ Hence, to quantify such influence in the present study, XRD analyses were conducted. To this end, two temperatures of 1000 and $1200{ }^{\circ} \mathrm{C}$ and oxidation times of 10 and 60 min were selected with the view to produce the maximum and minimum oxidation effects. The separated and powdered oxide layers were analysed and the results are provided in Figs. 6 and 7, for LNi and HNi steels, respectively.

As shown, while the three oxide layers could be identified, at a certain oxidation time for LNi, by increasing the oxidation temperature, the amount of magnetite would increase in opposition to that of hematite. Considering that hematite has a rougher surface compared to magnetite, a higher amount of it would cause the sample look darker ${ }^{[12]}$ In contrast, for HNi samples, where more magnetite is present in the oxide layer, the surface of sample looks brighter and with smoother surface, as shown in Fig. 8. It is also interesting to note that, in addition to the representative peaks of wustite, magnetite, and hamatite, the presence of spinel and chromite 
phases were detected in both steels that are in accordance with former studies. ${ }^{[43]}$ The effects of spinel and chromite phases will be discussed in details afterwards. Regarding the oxidized samples at $1200^{\circ} \mathrm{C}$ in Fig.8, some swollen lumps could be seen. These lumps, known as blisters, are due to a combination of generated stresses during scale formation and accumulation of $\mathrm{CO}$ and $\mathrm{CO} 2$ gas at the steel - oxide interface according to following reactions: ${ }^{[35,44]}$

$$
\begin{aligned}
& \mathrm{FeO}+\mathrm{C}=\mathrm{Fe}+\mathrm{CO} \\
& 2 \mathrm{FeO}+\mathrm{C}=2 \mathrm{Fe}+\mathrm{CO}_{2}
\end{aligned}
$$

\subsection{Role of Ni on compositional evolution of the oxide layers}

The effect of Ni content on the oxidation behaviour was studied in detail using Energydispersive X-ray spectroscopy (EDS). Fig. 9 shows the elemental map obtained for $\mathrm{O}$ and $\mathrm{Ni}$ for both alloys. One of the evident differences between the two steels is the presence of a $\mathrm{Ni}$ rich band on the top zone of transition layer in $\mathrm{HNi}$ steel. A $\mathrm{Cr}$ rich layer is present in the vicinity of the wustite zone for both alloys (see Fig. 13-b). The $\mathrm{Cr}$ concentration gradually decreases towards the base metal. Using the XRD analysis results reported in Figs. 6 and 7, the presence of spinel and $\mathrm{Cr}_{2} \mathrm{O}_{3}$ phases peaks could be inferred. Since the spinel composition is $\mathrm{FeOCr}_{2} \mathrm{O}_{3}$, it could be expected that this layer is placed between wustite and $\mathrm{Cr}_{2} \mathrm{O}_{3}$ phases. ${ }^{[43}$, ${ }^{45,46]}$ It should be also noted that $\mathrm{Cr}_{2} \mathrm{O}_{3}$ layer shows a decreasing gradient toward the base metal. However, as given in Fig. 10, the thickness of the $\mathrm{Cr}_{2} \mathrm{O}_{3}$ layer is thinner in the HNi steel (about $12 \mu \mathrm{m}$ in $\mathrm{LNi}$ and about $4 \mu \mathrm{m}$ in $\mathrm{HNi}$ ). From the Ni elemental map, shown in Fig. 10, it can be seen that the Ni rich layer and the spinel phases are placed in the same region in the HNi alloy. Therefore, it appears that the formation of the Ni rich layer between the spinel and the $\mathrm{Cr}_{2} \mathrm{O}_{3}$, results in a thinner $\mathrm{Cr}$ rich layer. 
The oxygen elemental map for $\mathrm{HNi}$, oxidized at $1200{ }^{\circ} \mathrm{C}$ for $10 \mathrm{~min}$, is shown in Fig. 9-a. The presence of an oxygen concentration gradient from the top oxide layer to the lower one is visible in this figure. Line scan analysis allowed for precise identification of the boundaries between the different layers, as well as the higher amount of oxygen for magnetite and hematite as compared to wustite as shown in Fig. 9-b.

Elemental map analysis of $\mathrm{Ni}$ at the interface of base metal - wustite (zone A in Fig. 5-a) showed that this zone is richer in Ni than the base metal. This enrichment, as shown in Fig.10-a, is probably due to the fact that $\mathrm{Ni}$ is more noble than iron and therefore it accumulates at the oxide-metal interface. ${ }^{[47]}$ As will be shown below, the diffusion of $\mathrm{Ni}$ in iron is very slow and as a result, it could not diffuse back rapidly to iron and will concentrate at the oxide-metal interface. The above observations are in support of those by other researchers who reported that the $\mathrm{Ni}$ enrichment at the interface for $\mathrm{Fe}-1 \mathrm{wt} \% \mathrm{Ni}$ alloy, oxidized at $1000{ }^{\circ} \mathrm{C}$, almost approached $70 \mathrm{wt} \% .^{[48]}$ The higher concentration of $\mathrm{Ni}$ at the oxide-metal will increase the resistance to oxidation.

One possible operating mechanisms of $\mathrm{Ni}$ as oxidation barrier could be in terms of its influence on the diffusion of both oxygen and iron in the oxide layer as compared to the austenite lattice. The calculations were done at all tested temperatures; however, only those at 1200C are shown as they better illustrate the impact of Ni: Oxygen diffusion in the iron lattice was calculated based on the work published by Takada and Adachi: ${ }^{[49]}$

$$
D=\left(2.91_{-1.57}^{+3.40}\right) \times 10^{-3} \cdot \exp \left(\frac{-89.5}{R \times 1200}\right)
$$


where $\mathrm{D}$ is diffusion coefficient $\left(\mathrm{cm}^{2} \cdot \mathrm{sec}^{-1}\right), \mathrm{R}$ is gas constant $\left(\mathrm{J} \cdot \mathrm{mol}^{-1} \cdot \mathrm{K}^{-1}\right)$, and $\mathrm{T}$ is temperature $\left({ }^{\circ} \mathrm{K}\right)$. Similarly, the diffusion of oxygen in $\mathrm{Ni}$ was calculated as reported by Garruchet et al. ${ }^{[50]}$ and Nam et al. ${ }^{[51]}$. The results indicated that the diffusion of oxygen in iron at $1200 \mathrm{C}$ is about $2.88 \times 10^{-3}\left(\mathrm{~cm}^{2} \cdot \mathrm{sec}^{-1}\right)$ and $4.6 \times 10^{-6}\left(\mathrm{~cm}^{2} \cdot \mathrm{sec}^{-1}\right)$ in $\mathrm{Ni}$, (i.e. it is almost 1000 times slower in Ni). Furthermore, Buffington et al. ${ }^{[52]}$ reported that the self-diffusivity of iron at $1200{ }^{\circ} \mathrm{C}$ is equal to $2.8 \times 10^{-4}\left(\mathrm{~cm}^{2} \cdot \mathrm{sec}^{-1}\right)$ which is almost $10^{6}$ times faster than in $\mathrm{Ni}, 2.58 \times 10^{-}$ ${ }^{10}\left(\mathrm{~cm}^{2} \cdot \mathrm{sec}^{-1}\right) \cdot{ }^{[53]}$ Consequently, a Ni rich layer will be produced that will limit the accessibility of oxygen and iron to each other and will significantly delay the oxidation process.

Fig. 11 shows that in the transition layer, oxygen and silicon ( $\mathrm{Si}$ ) have produced a network of particles at the grain boundaries, which could be related to the higher affinity of Si to oxygen as compared to $\mathrm{Mn}, \mathrm{Cr}, \mathrm{Fe}$, and $\mathrm{Ni}$, in accordance with the Ellingham diagram. ${ }^{[54]}$ On the other hand, once the oxide is formed at the grain boundary, a Fe depleted zone would develop on both sides of the grain boundary, creating a driving force that will fuel the movement of alloying elements from grain interior toward the grain boundaries.

Apart from higher thermodynamic stability of $\mathrm{SiO}_{2}$ oxides, in terms of kinetic approach, $\mathrm{Si}$ has higher diffusivity in $\mathrm{Fe}$ compared to other alloying elements like $\mathrm{Ni}$ and $\mathrm{Cr}$ or even selfdiffusion of Fe atoms. ${ }^{[55]}$ Hence, Si would produce the initial protection layer at the lower surface of the transition layer at the oxide-metal interface. ${ }^{[52,56]}$ As is demonstrated in Fig. 12, Mo demonstrates to segregate in the same site as of $\mathrm{Ni}$ in transition layer.

The concentration of alloying element increases mainly in bulk rather than metal surface, in case that the diffusion coefficient of alloying element is higher than the oxidation rate. ${ }^{[21]}$ Alloying elements such as $\mathrm{Ni}$ or oxides such as $\mathrm{SiO}_{2}$ and $\mathrm{Cr}_{2} \mathrm{O}_{3}$, remain in the transition zone (see Fig. 13). Also, $\mathrm{Cr}$ is rejected at scale-metal interface, making a $\mathrm{Cr}$ rich layer and reducing 
the oxidation. One of the critical factors in reducing the oxidation is the formation of $\mathrm{Fe}-\mathrm{Cr}$ spinel next to base metal. ${ }^{[28,46]}$ Furthermore, in this region, iron oxides were also detected as network of discrete grains (internal oxidation), which should be evidently in type of wustite. These grains are shown in Fig. 14 and related to initial stages of oxidation by former studies. ${ }^{[2,}$ 42]

\section{Conclusions}

To investigate the effect of $\mathrm{Ni}$ on high temperature oxidation of steels, thermogravimetry and direct oxidation experiments were employed to oxidize two steels with different $\mathrm{Ni}$ concentration. The provided samples were assessed in terms of mass gain and investigated by means of SEM, EDS and XRD. The obtained outcomes are as follows:

- By increasing the oxidation time and oxidation temperature, the oxidation rate of both LNi and HNi steels increased. The oxidation rate was increasing faster at the initial stages of oxidation, but it decreased gradually by time.

- The oxidation of the HNi steel was less than that of the LNi steel for all tested conditions.

- The activation energies were calculated as 238 and $275 \mathrm{KJ}^{-\mathrm{mol}^{-1}}$ for $\mathrm{LNi}$ and $\mathrm{HNi}$, respectively, demonstrating the higher resistance to oxidation for the steel rich in $\mathrm{Ni}$.

- The oxide layers were thinner on the HNi steel compared to the LNi, but the fraction of sub-layers to the overall oxide remained the same for both steels. 
- For oxidation at $1200{ }^{\circ} \mathrm{C}$, blisters were observed on oxide surfaces due to generated stress during oxidation and accumulation of $\mathrm{CO}$ and $\mathrm{CO}_{2}$ gas at the interface of oxide metal.

- The oxide - metal interface was rougher for HNi steel compared to LNi, with thicker transition layer, which would decrease the scale removability.

- EDS analysis revealed a gradient of oxygen concentration from top oxide layer way to lower layer direction. Ni was more enriched in wustite compared to the base metal. Due to its low diffusivity, $\mathrm{Ni}$ was accumulated at the oxide-metal interface and made an additional bond. This bond would resist against oxidation and decrease the scale removability, as the transition layer was thicker in the HNi steel. Chromium is rejected at the interface of oxide-metal and makes a resistance against oxidation by forming a spinel layer next to base metal.

- The spinel composition of $\mathrm{FeOCr}_{2} \mathrm{O}_{3}$ was placed between wustite and $\mathrm{Cr}_{2} \mathrm{O}_{3}$. The thickness of $\mathrm{Cr}_{2} \mathrm{O}_{3}$ was thinner in $\mathrm{HNi}$ steel. The spinel phase was placed in the same site as Ni rich layer. This issue would impede the interaction between $\mathrm{FeO}$ and $\mathrm{Cr}_{2} \mathrm{O}_{3}$, causing thinner $\mathrm{Cr}$ rich layer.

- Considering the lower diffusivity of oxygen in Ni compared to iron lattice, and faster self-diffusivity of iron in comparison with its diffusion in $\mathrm{Ni}$, a $\mathrm{Ni}$ rich layer would confine the accessibility of oxygen and iron to each other and consequently decrease the oxidation. 


\section{Acknowledgment}

The authors are very much grateful to Finkl Steel for providing the specimens for the present research. The authors would also like to thank National Science Engineering Research Council (NSERC) Canada for their support in the framework of a Collaborative Research and Development project (CRD).

\section{Data Availability}

- The raw/processed data required to reproduce these findings cannot be shared at this time due to legal or ethical reasons.

- The raw/processed data required to reproduce these findings cannot be shared at this time as the data also forms part of an ongoing study. 


\section{References}

[1] H. Utsunomiya, S. Doi, K.-i. Hara, T. Sakai, S. Yanagi, CIRP annals 2009, 58, 271.

[2] X. Yu, Z. Jiang, J. Zhao, D. Wei, J. Zhou, C. Zhou, Q. Huang, Surface and Coatings Technology 2015, 277, 151.

[3] S. Mrowec, Z. Grzesik, Journal of Physics and Chemistry of Solids 2004, 65, 1651.

[4] P.A. Munther, J.G. Lenard, Journal of Materials Processing Technology 1999, 88, 105.

[5] L. Suarez, Y. Houbaert, X.V. Eynde, R. Colás, Corrosion Science 2009, 51, 309.

[6] A. Vijh, Journal of materials science 1974, 9, 985.

[7] K. Wakasa, M. Yamaki, Journal of materials science 1988, 23, 1459.

[8] H. Abuluwefa, R. Guthrie, F. Ajersch, Oxid Met 1996, 46, 423.

[9] O. Zambrano, J. Coronado, S. Rodríguez, Surface and Coatings Technology 2015, 282, 155.

[10] R. Chen, W. Yuen, Oxid Met 2000, 53, 539.

[11] R. Chen, W. Yeun, Oxid Met 2003, 59, 433.

[12] S. Liu, D. Tang, H. Wu, L. Wang, Journal of Materials Processing Technology 2013, 213, 1068.

[13] G.-m. Cao, X.-j. Liu, S. Bin, Z.-y. Liu, Journal of Iron and Steel Research, International 2014, 21, 335 .

[14] V.V. Basabe, J.A. Szpunar, steel research international 2006, 77, 818.

[15] J. Baud, A. Ferrier, J. Manenc, Oxid Met 1978, 12, 331. 
[16] H. Abuluwefa, R. Guthrie, F. Ajersch, Metallurgical and Materials Transactions A 1997, $28,1633$.

[17] J.Y. Yun, S.A. Ha, C.Y. Kang, J.P. Wang, steel research international 2013, 84, 1252.

[18] S.V. Kumari, V. Vaidyan, K. Sathyanarayana, Journal of materials science 1991, 26, 1899.

[19] C. Wang, J. Duh, Journal of materials science 1988, 23, 3447.

[20] C. Kao, C. Wan, Journal of materials science 1988, 23, 1943.

[21] M. Krzyzanowski, J.H. Beynon, ISIJ international 2006, 46, 1533.

[22] J. Von Fraunhofer, G. Pickup, Anti-Corrosion Methods and Materials 1970, 17, 10.

[23] A. Rahmel, M. Schütze, W. Quadakkers, Materials and Corrosion 1995, 46, 271.

[24] B.A. Webler, S. Sridhar, ISIJ international 2007, 47, 1245.

[25] T. Asai, T. Soshiroda, M. Miyahara, ISIJ international 1997, 37, 272.

[26] Z.F. Li, G.M. Cao, Y.Q. He, Z.Y. Liu, G.D. Wang, steel research international 2016, 87, 1469.

[27] I. Kim, W. Cho, H. Kim, Journal of materials science 2000, 35, 4695.

[28] M. Takeda, H. Kushida, T. Onishi, M. Toyama, F. Koizumi, S. Fujimoto, Oxid Met 2010, $73,1$.

[29] A. Laukka, E.P. Heikkinen, T. Fabritius, steel research international 2019, 90, 1800447.

[30] D.J. Young, High temperature oxidation and corrosion of metals, Elsevier, 2008.

[31] R. Jha, C.W. Haworth, B.B. Argent, Calphad 2001, 25, 667. 
[32] J. Yuan, W. Wang, S. Zhu, F. Wang, Corrosion Science 2013, 75, 309.

[33] B. Pujilaksono, T. Jonsson, M. Halvarsson, J.-E. Svensson, L.-G. Johansson, Corrosion Science 2010, 52, 1560.

[34] H. Yin, S. Chan, W. Yuen, D. Young, Oxid Met 2012, 77, 305.

[35] M. Nagl, W. Evans, Journal of Materials Science 1993, 28, 6247.

[36] S.A. Bradley, T.L. Barr, K.J. Youtsey, Journal of Materials Science 1979, 14, 2317.

[37] L. Suárez, Y. Houbaert, X.V. Eynde, R. Colás, Oxid Met 2008, 70, 1.

[38] N. Birks, G.H. Meier, F.S. Pettit, Introduction to the high temperature oxidation of metals, Cambridge University Press, 2006.

[39] R. Chen, W. Yuen, ISIJ international 2005, 45, 52.

[40] N. Madern, J. Monnier, R. Baddour-Hadjean, A. Steckmeyer, J.-M. Joubert, Corrosion Science 2018, 132, 223.

[41] O. Barrau, C. Boher, R. Gras, F. Rezai-Aria, Wear 2003, 255, 1444.

[42] M. Krzyzanowski, J.H. Beynon, D.C. Farrugia, Oxide scale behavior in high temperature metal processing, John Wiley \& Sons, 2010.

[43] H. Falk-Windisch, J.E. Svensson, J. Froitzheim, Journal of Power Sources 2015, 287, 25.

[44] Y. Kondo, H. Tanei, N. Suzuki, K. Ushioda, M. Maeda, ISIJ international 2011, 51, 1696.

[45] L. Chen, Z. Zhou, Z. Tan, D. He, K. Bobzin, L. Zhao, M. Öte, T. Königstein, Journal of Alloys and Compounds 2018.

[46] J. Yuan, X. Wu, W. Wang, S. Zhu, F. Wang, Oxid Met 2013, 79, 541.

[47] T.-K. Tsao, A.-C. Yeh, C.-M. Kuo, H. Murakami, Entropy 2016, 18, 62. 
[48] Y.N. Chang, F.I. Wei, Journal of materials science 1989, 24, 14.

[49] J. Takada, M. Adachi, Journal of materials science 1986, 21, 2133.

[50] S. Garruchet, O. Politano, P. Arnoux, V. Vignal, Solid State Commun. 2010, 150, 439.

[51] H.O. Nam, J.Y. Yoon, J.H. Kim, I.S. Hwang, K.H. Lee, Proceedings of the 15th International Conference on Environmental Degradation of Materials in Nuclear Power Systems-Water Reactors, Springer, 2011, pp. 1463.

[52] F. Buffington, K.-i. Hirano, M. Cohen, Acta Metall. 1961, 9, 434.

[53] C.F. Heuer, Missouri University of Science and Technology, 1969.

[54] H. Bhadeshia, R. Honeycombe, Steels: microstructure and properties, ButterworthHeinemann, 2017.

[55] J.C. Slater, The Journal of Chemical Physics 1964, 41, 3199.

[56] E. Brandes, G. Brook, P. Paufler, Crystal Research and Technology 1993, 28, 530. 
Table 1 Chemical composition of employed steels in current study (wt\%).

\begin{tabular}{|c|c|c|c|c|c|c|c|}
\hline & $\mathrm{C}$ & $\mathrm{Mn}$ & $\mathrm{Si}$ & $\mathrm{Ni}$ & $\mathrm{Cr}$ & Mo & $\mathrm{Cu}$ \\
\hline LNi & 0.35 & 0.99 & 0.41 & 0.5 & 1.86 & 0.53 & 0.16 \\
\hline $\mathrm{HNi}$ & 0.35 & 0.99 & 0.41 & 2.92 & 1.86 & 0.53 & 0.16 \\
\hline
\end{tabular}


Table 2 Chemical composition of employed steels in former studies for activation energy of oxidation (wt\%).

$\begin{array}{lllllll}\text { Activation } & \mathrm{C} & \mathrm{Ni} & \mathrm{Mn} & \mathrm{Si} & \mathrm{Cr} & \mathrm{Mo}\end{array}$

\begin{tabular}{l|c|cccccc}
\hline Yuan et al. [1] & 205 & 0.011 & 0.018 & 0.035 & 0.028 & 0.01 & 0.005 \\
Abuluwefa et al. [2] & $127 \pm 7$ & 0.04 & 0.03 & 0.2 & 0.02 & 0.04 & 0.01 \\
Liu et al. [3] & 105 & 0.04 & 0.02 & 1.56 & 0.23 & 0.02 & 0.17 \\
Munther and Lenard [4] & 124 & 0.18 & - & 0.71 & 0.21 & - & - \\
Madern et al. [5] & 280 & 0.4 & 33.5 & 1.5 & 1.6 & 5 & - \\
Present Study (LNi) & 238 & 0.35 & 0.5 & 0.99 & 0.41 & 1.86 & 0.53 \\
Present Study (HNi) & 275 & 0.35 & 2.92 & 0.99 & 0.41 & 1.86 & 0.53
\end{tabular}




\section{Caption list}

Fig. 1 Heating cycle for thermogravimetric analysis

Fig. 2 MTS machine with an installed radiative furnace

Fig. 3 Squared mass gain per unit surface for oxidation of LNi at: a) $1000{ }^{\circ} \mathrm{C}$, b) $1100{ }^{\circ} \mathrm{C}$, c) $1150{ }^{\circ} \mathrm{C}$ and d) $1200{ }^{\circ} \mathrm{C}$; and $\mathrm{HNi}$ at: e) $1000{ }^{\circ} \mathrm{C}$, f) $1100{ }^{\circ} \mathrm{C}$, g) $1150{ }^{\circ} \mathrm{C}$ and h) $1200{ }^{\circ} \mathrm{C}$

Fig. 4 Activation energies for oxidation of: a) LNi and b) HNi steels

Fig. 5 LEXT laser confocal image from oxide layers of sample oxidized at $1000{ }^{\circ} \mathrm{C}$ for $60 \mathrm{~min}$ :

a) $\mathrm{LNi}$, b) $\mathrm{HNi}$, c) Stitched image of LNi and d) Stitched image of $\mathrm{HNi}$

Fig. 6 XRD analysis of LNi steel oxide powder for oxidation time intervals of: a) 10 and b) 60 $\min$

Fig. 7 XRD analysis of $\mathrm{HNi}$ steel oxide powder for oxidation time intervals of: a) 10 and b) 60 $\min$

Fig. 8 Surfaces of $\mathrm{HNi}$ samples oxidized at $1000{ }^{\circ} \mathrm{C}$ and $1200{ }^{\circ} \mathrm{C}$ for 10 and $60 \mathrm{~min}$

Fig. $9 \mathrm{HNi}$ steel, oxidized at $1200{ }^{\circ} \mathrm{C}$ for $10 \mathrm{~min}$ : a) oxygen elemental map, and b) oxygen line analysis (red line), (green line is the variation of Fe element)

Fig. 10 Oxidized at $1200{ }^{\circ} \mathrm{C}$ for $10 \mathrm{~min}$ : a) $\mathrm{Ni}$ elemental map for $\mathrm{HNi}$, and b) $\mathrm{Cr}$ elemental map for $\mathrm{LNi}$ (left) and $\mathrm{HNi}$ (right)

Fig. 11 The network of particles made from oxygen and Si in grain boundaries of HNi steel, oxidized at $1200{ }^{\circ} \mathrm{C}$ for $10 \mathrm{~min}$

Fig. 12 Mo segregation in transition zone of oxide of $\mathrm{HNi}$ steel, oxidized at $1200{ }^{\circ} \mathrm{C}$ for $10 \mathrm{~min}$ Fig. 13 Remained a) $\mathrm{SiO} 2$ and b) $\mathrm{Cr} 2 \mathrm{O} 3$ oxide in transition

Fig. 14 Spherical shape oxides in type of wustite for $\mathrm{HNi}$ steel, oxidized at $1200{ }^{\circ} \mathrm{C}$ for $10 \mathrm{~min}$ 


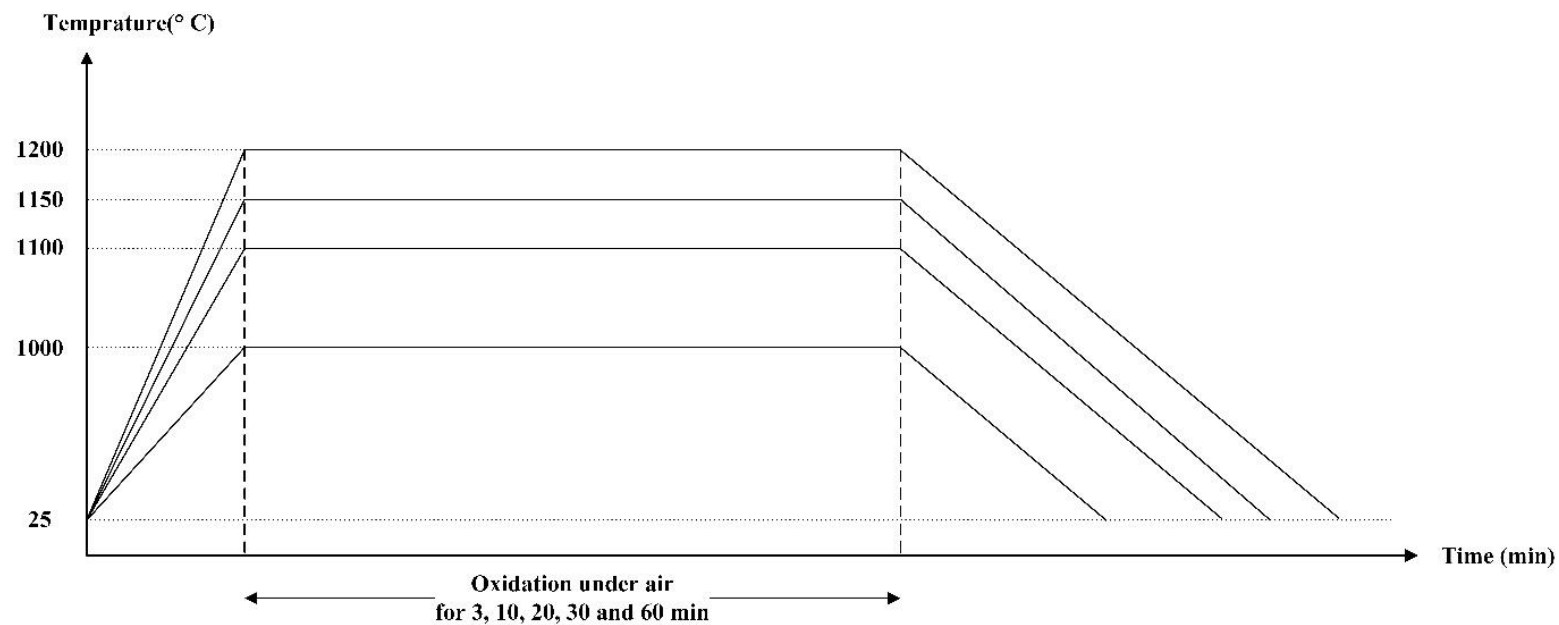

Fig. 1 Heating cycle for thermogravimetric analysis 

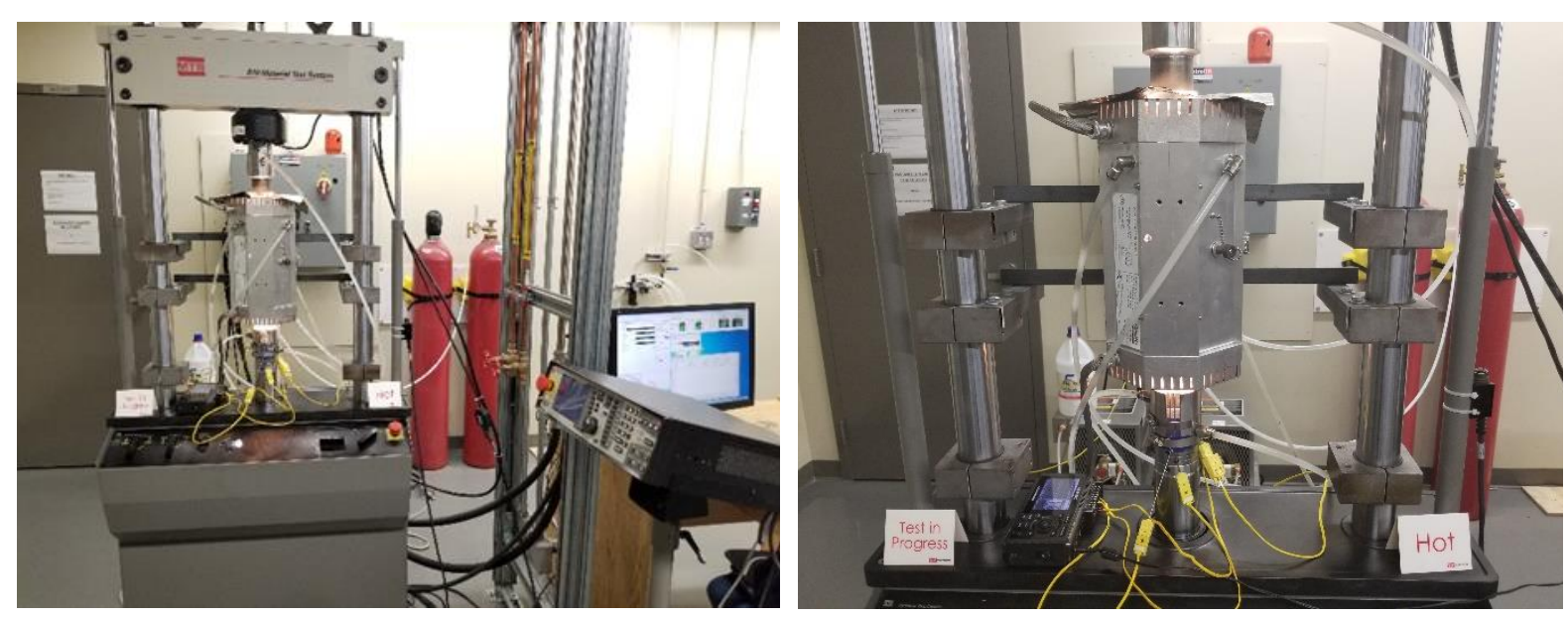

Fig. 2 MTS machine with an installed radiative furnace 


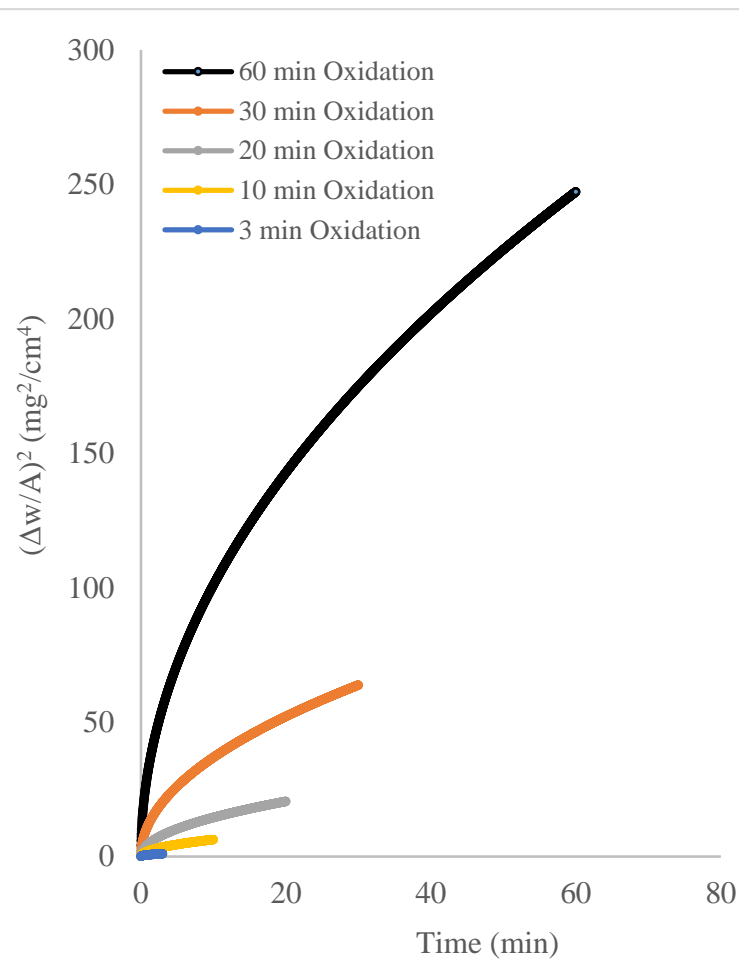

(a)

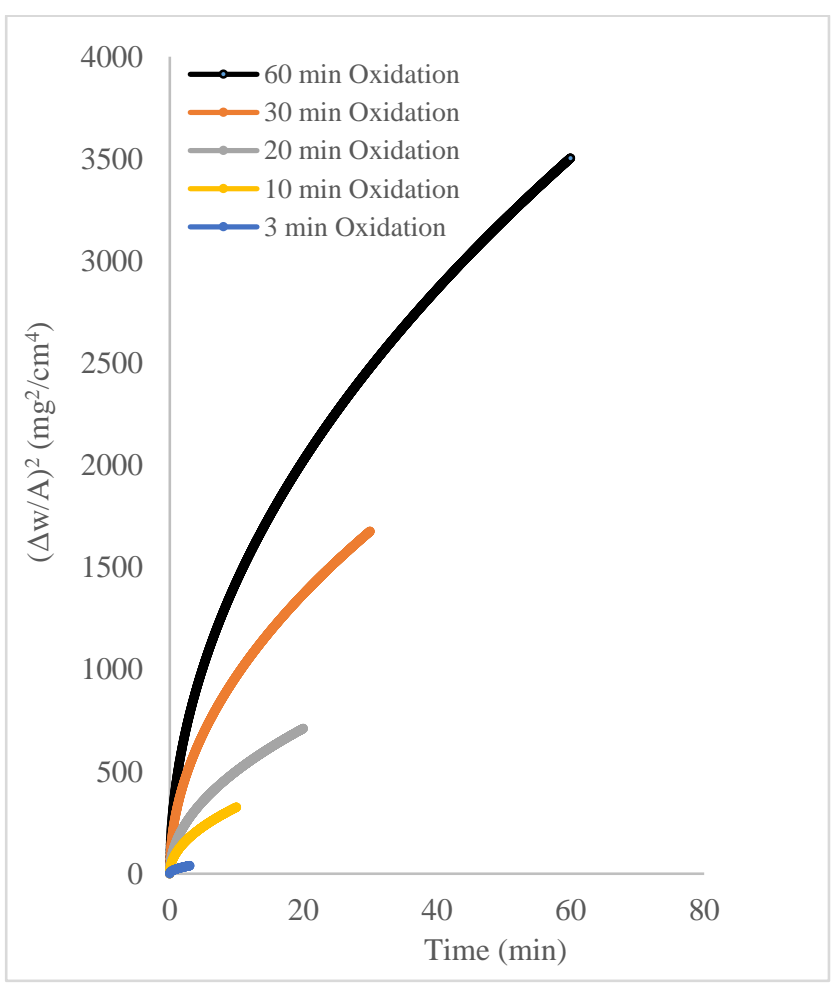

(c)

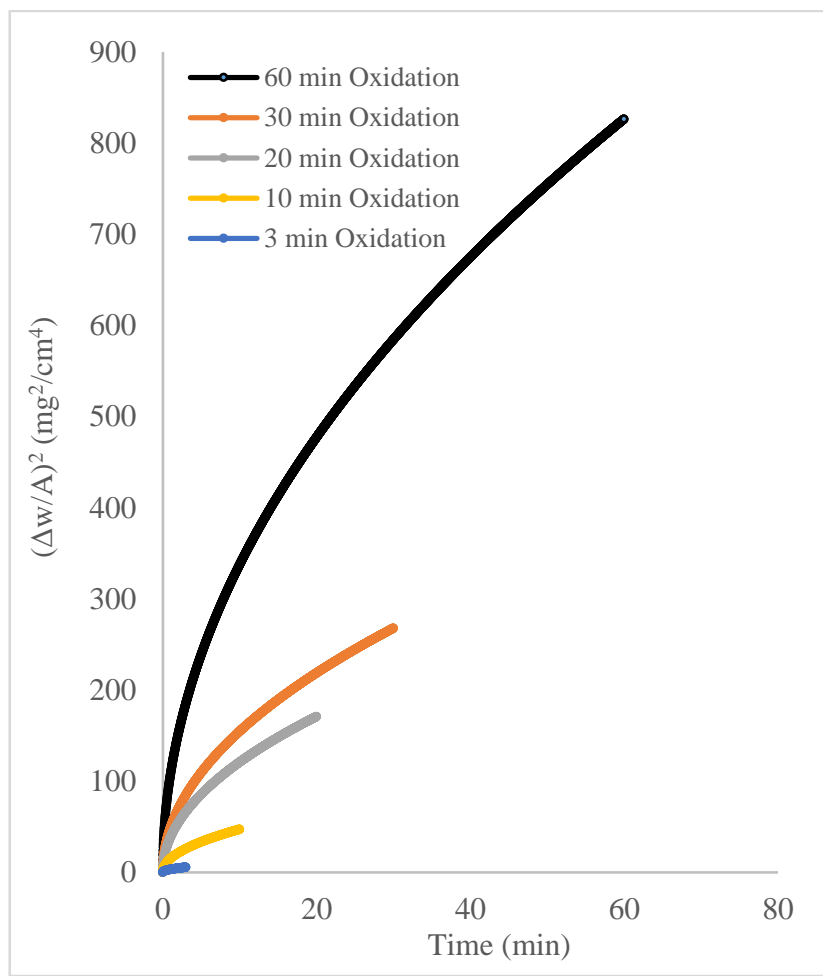

(b)

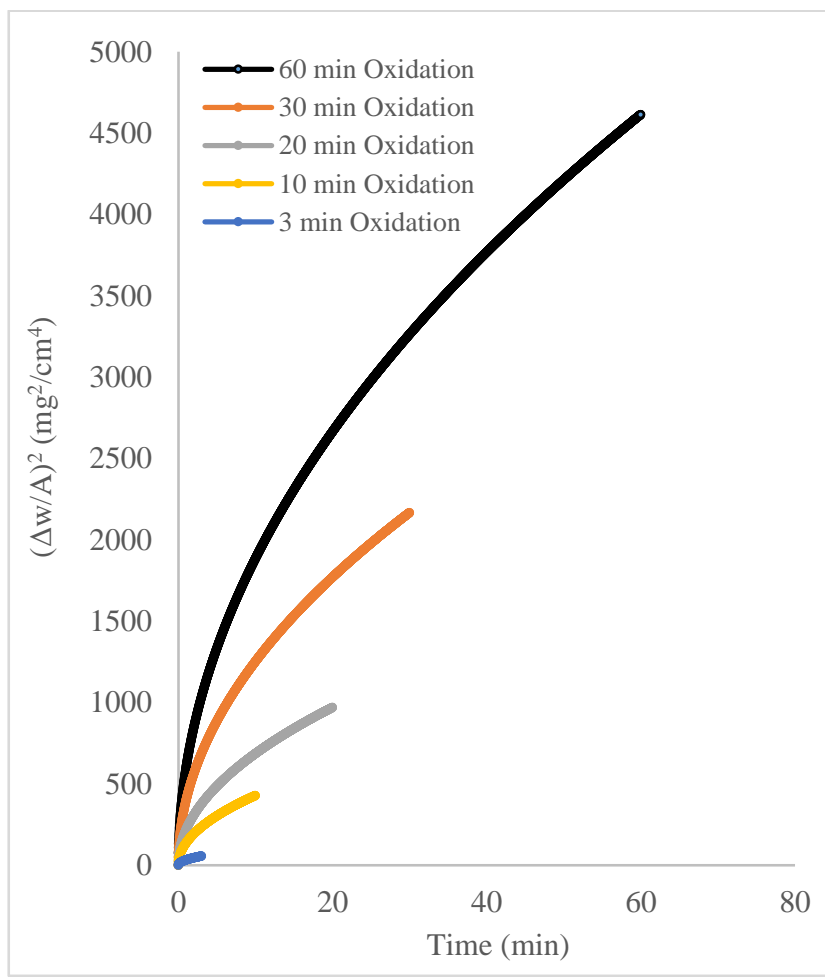

(d) 


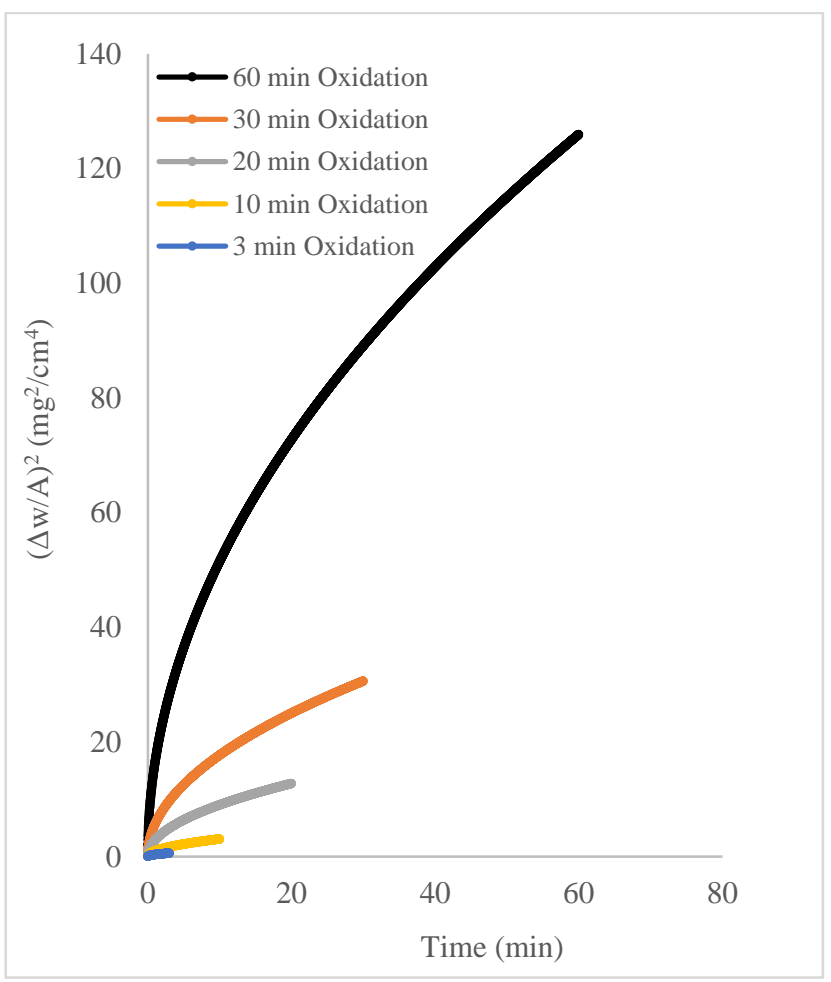

(e)

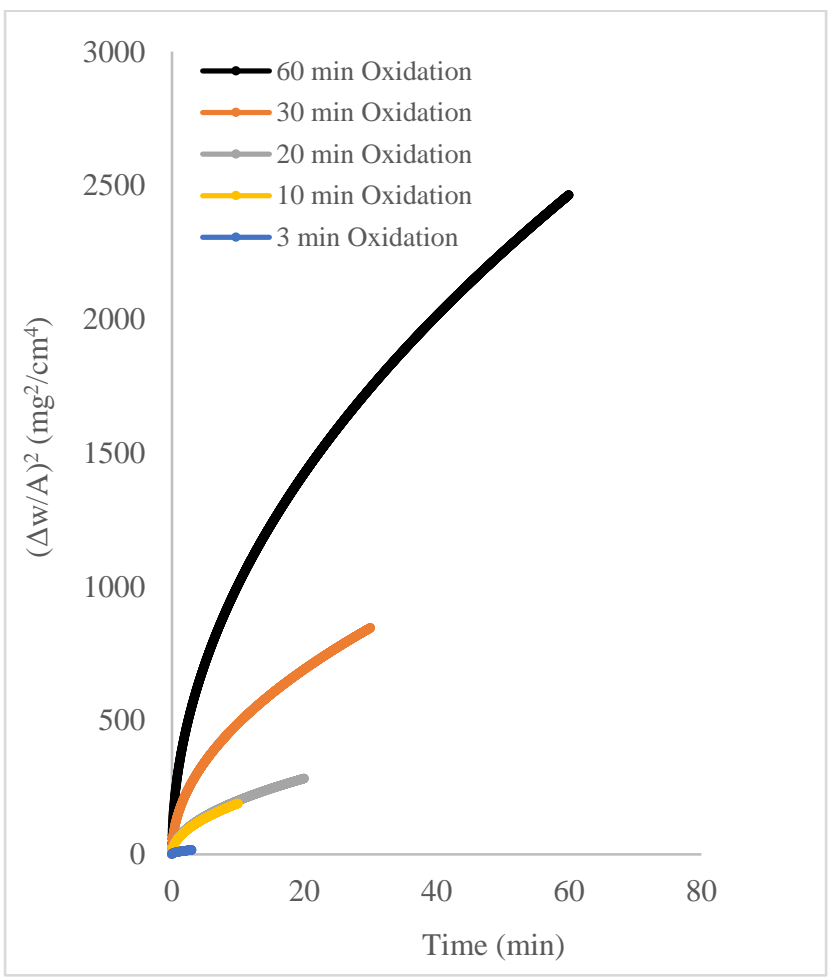

(g)

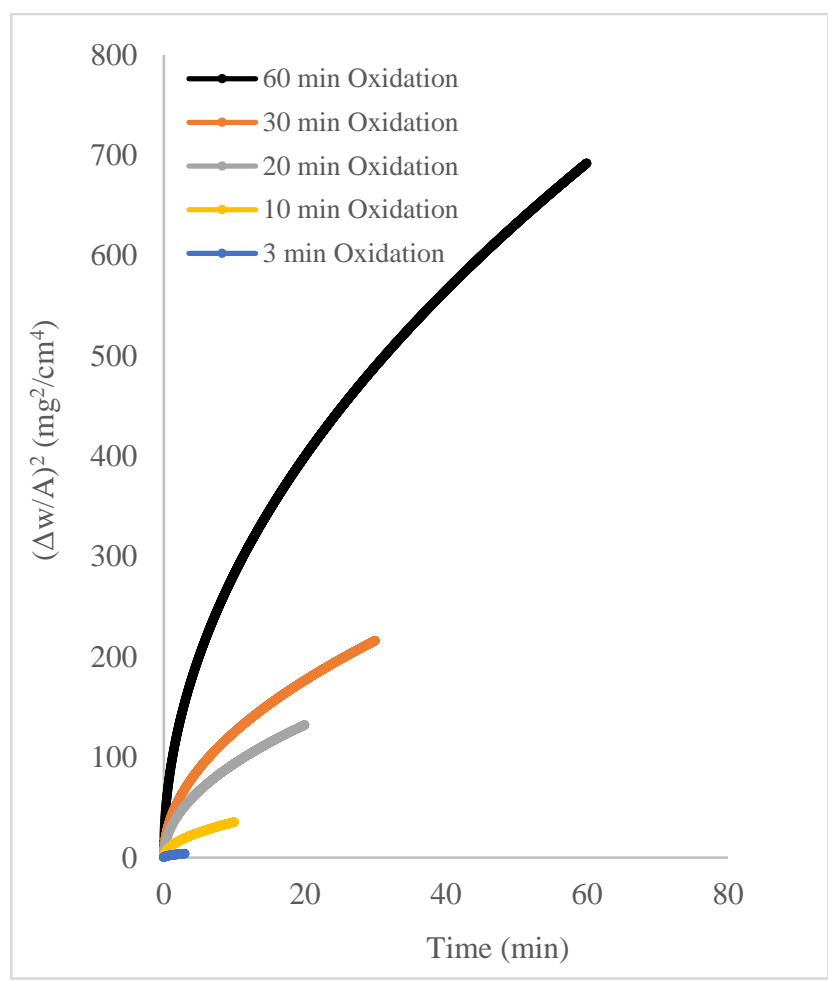

(f)

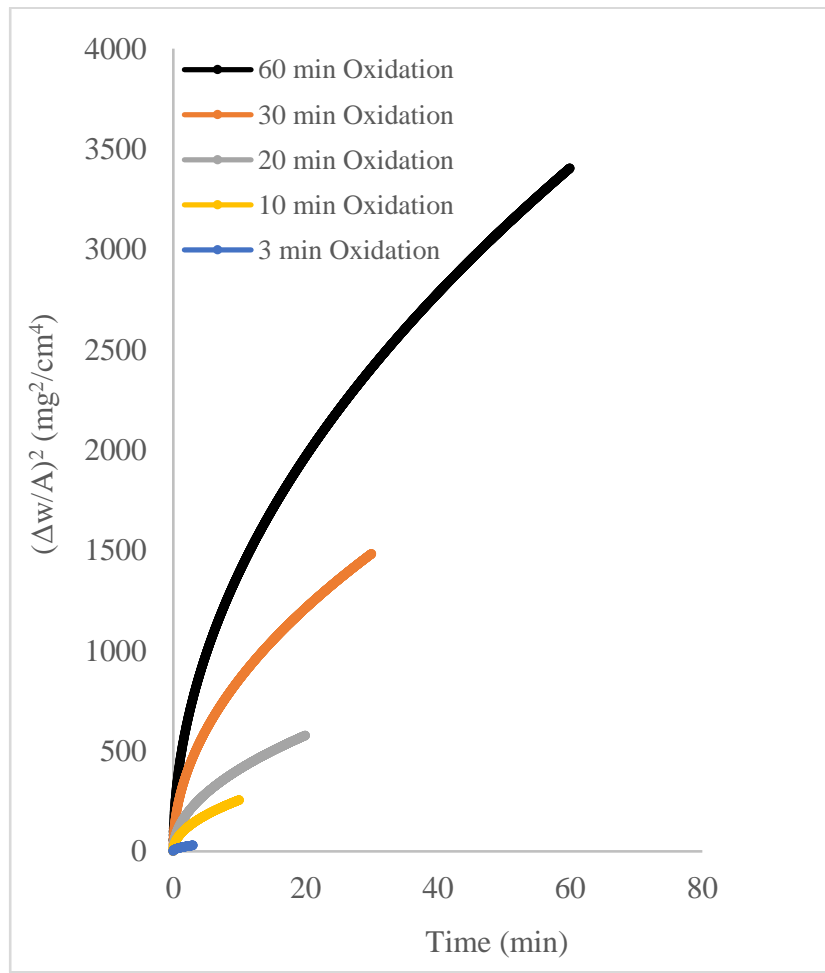

(h) 
Fig. 3 Squared mass gain per unit surface for oxidation of $\mathrm{LNi}$ at: a) $1000{ }^{\circ} \mathrm{C}$, b) $1100{ }^{\circ} \mathrm{C}$, c) $1150{ }^{\circ} \mathrm{C}$ and d) $1200{ }^{\circ} \mathrm{C}$; and $\mathrm{HNi}$ at: e) $1000{ }^{\circ} \mathrm{C}$, f) $1100{ }^{\circ} \mathrm{C}$, g) $1150{ }^{\circ} \mathrm{C}$ and h) $1200{ }^{\circ} \mathrm{C}$ 


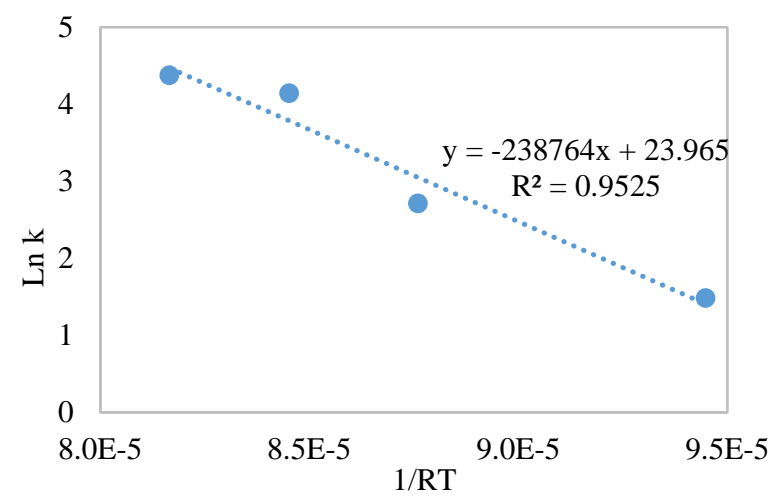

(a)

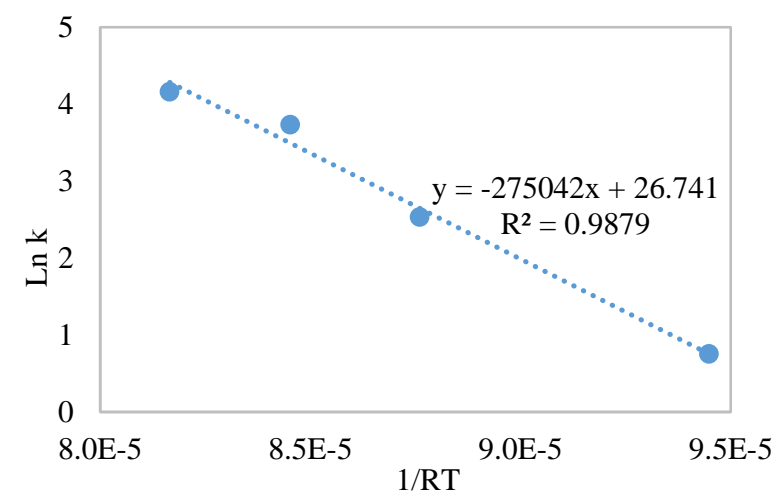

(b)

Fig. 4 Activation energies for oxidation of: a) LNi and b) HNi steels 


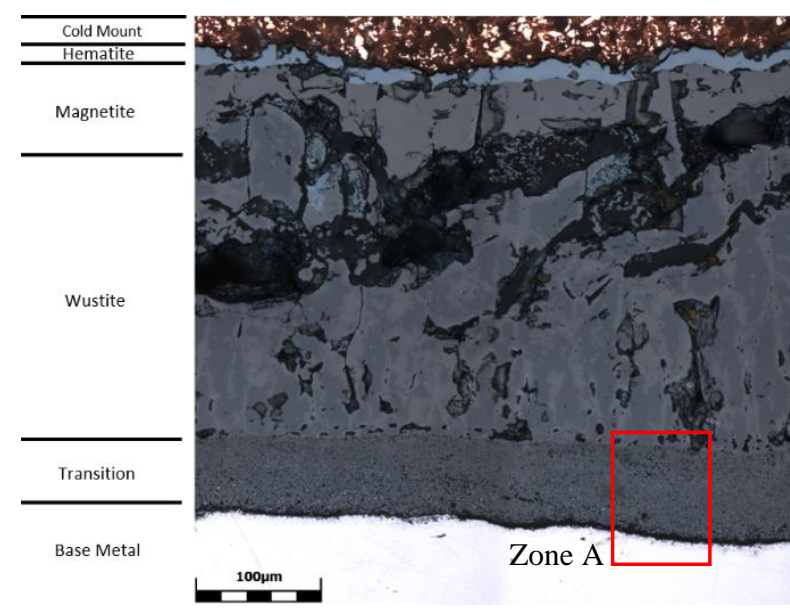

(a)

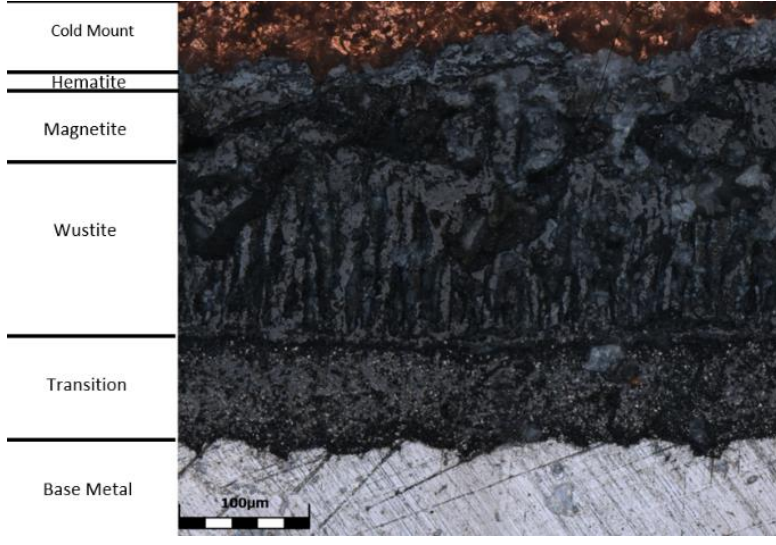

(b)

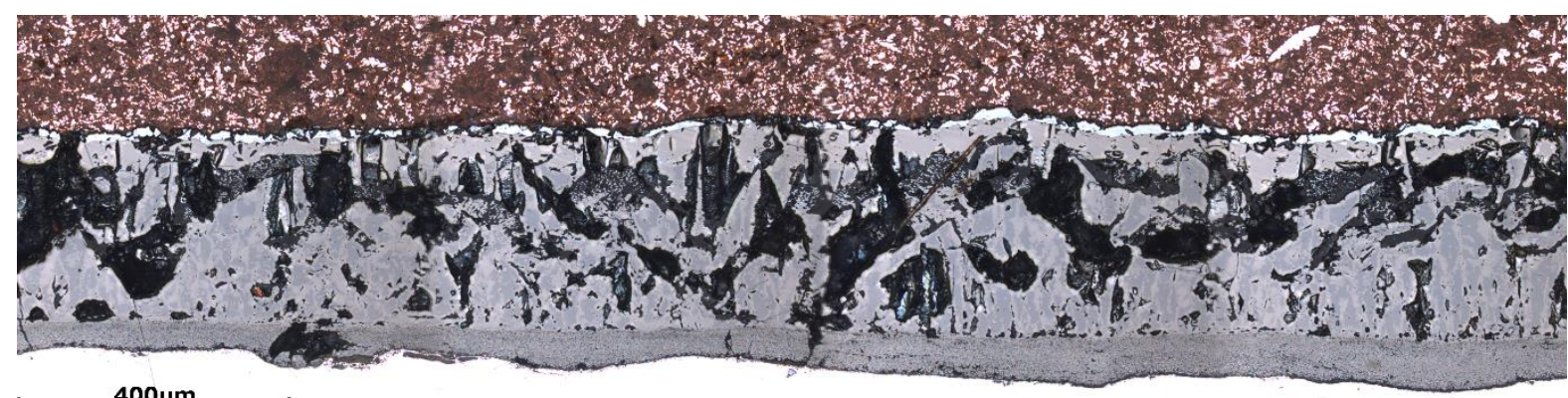

(c)

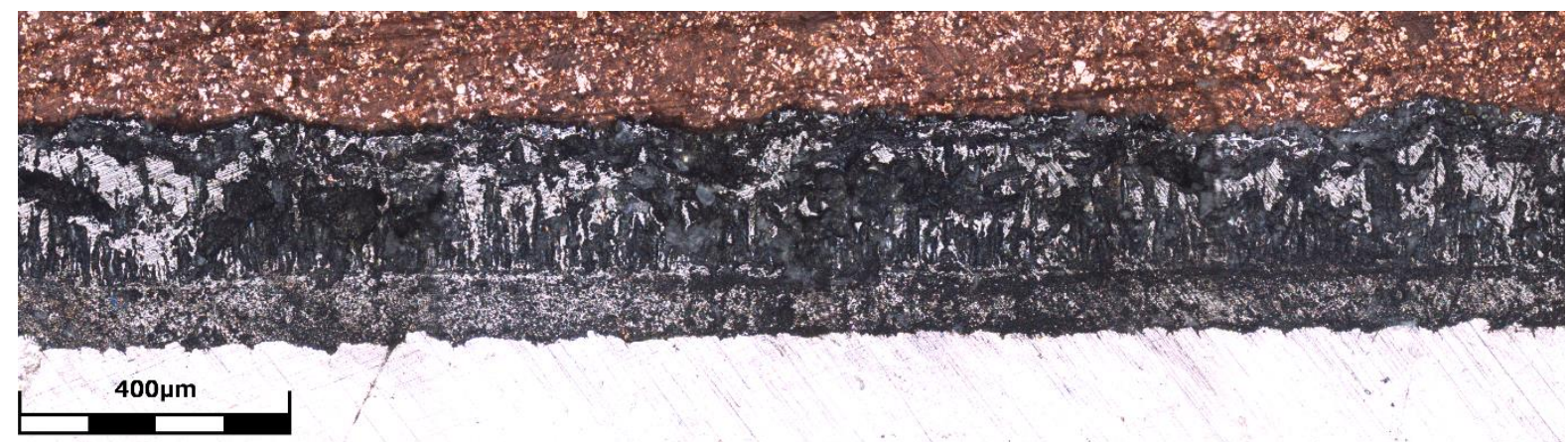

(d)

Fig. 5 LEXT laser confocal image from oxide layers of sample oxidized at $1000{ }^{\circ} \mathrm{C}$ for 60 min: a) LNi, b) HNi, c) Stitched image of LNi and d) Stitched image of HNi 


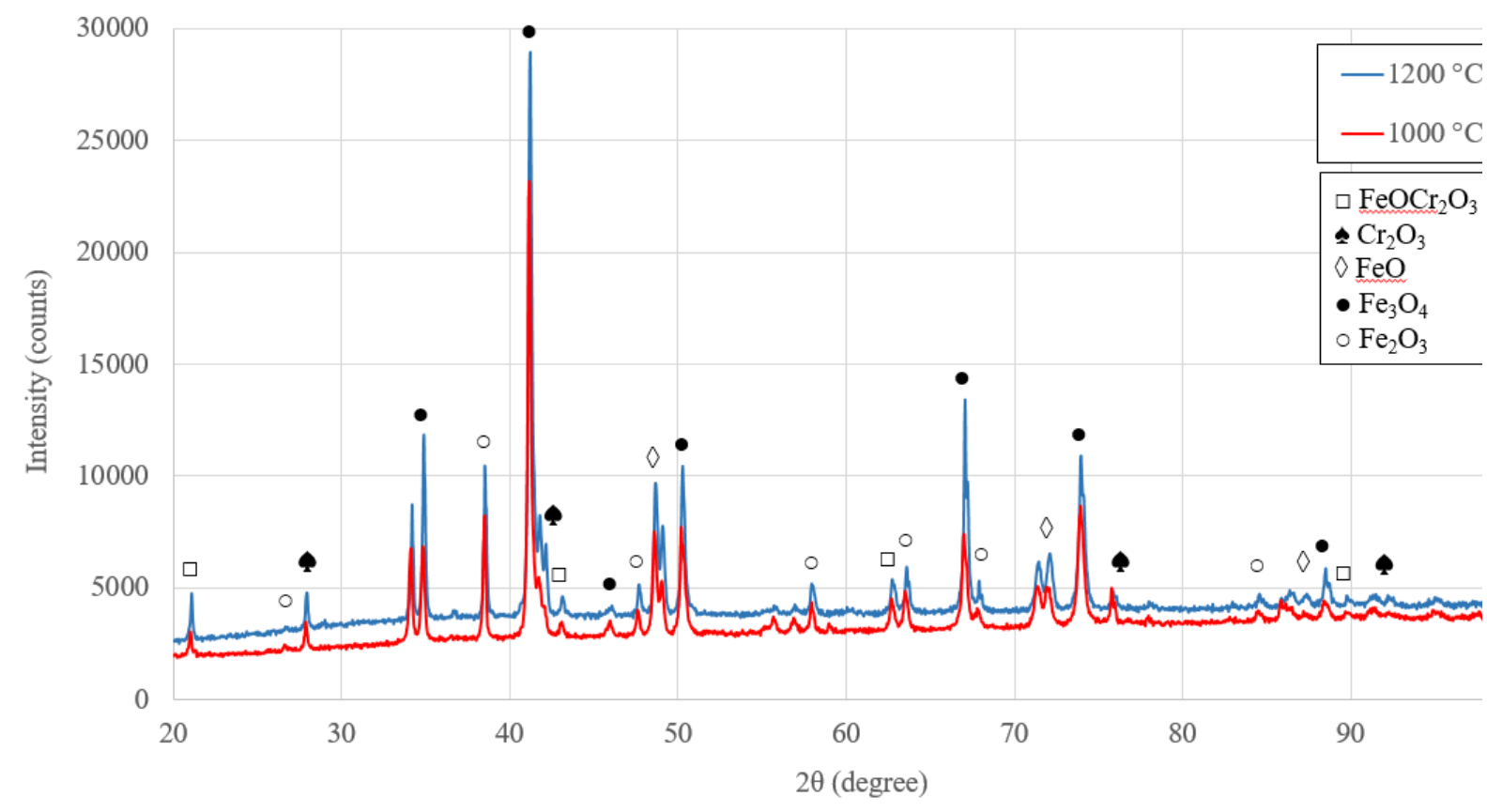

(a)

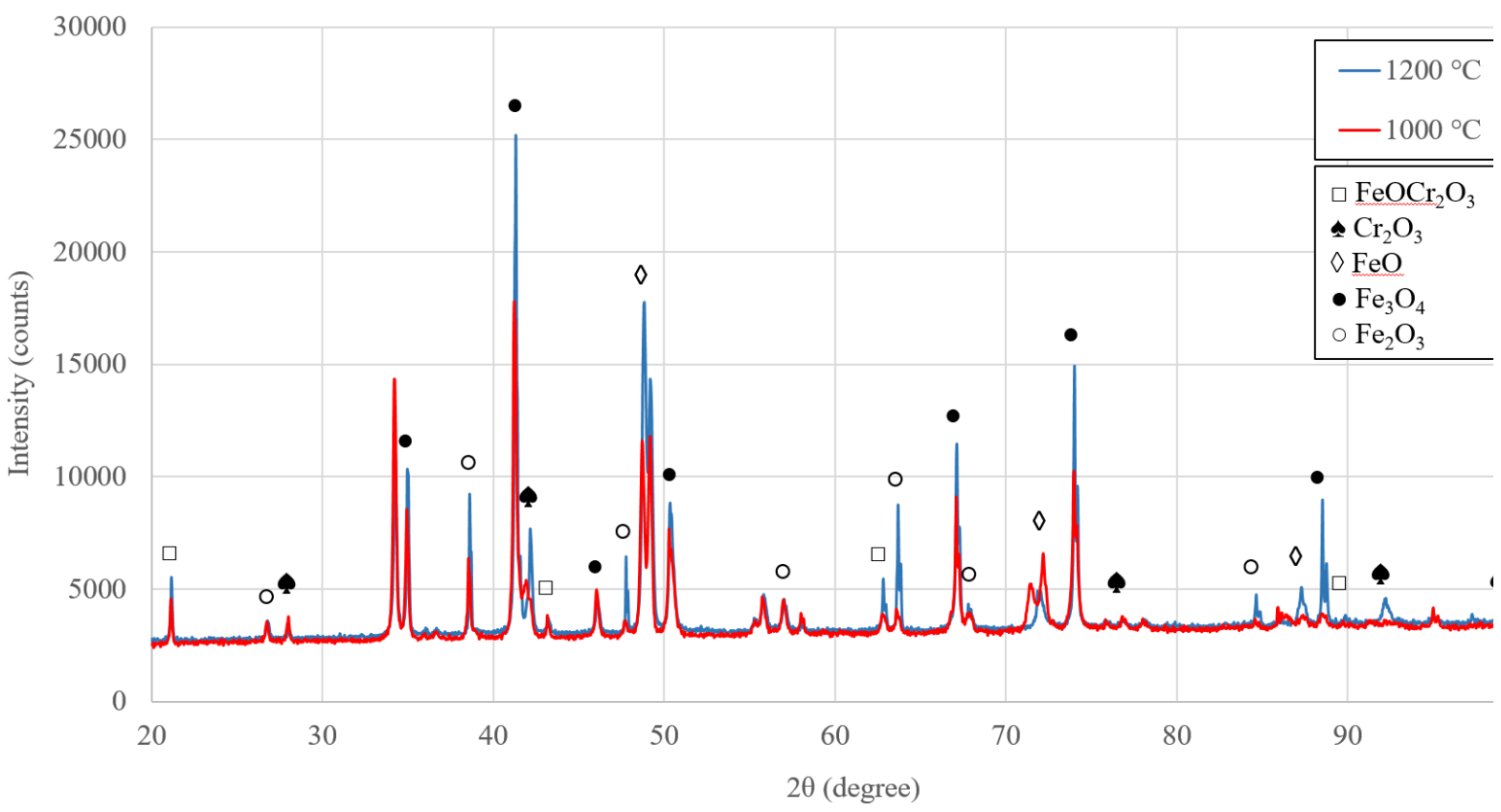

(b)

Fig. 6 XRD analysis of LNi steel oxide powder for oxidation time intervals of: a) 10 and b) $60 \mathrm{~min}$ 


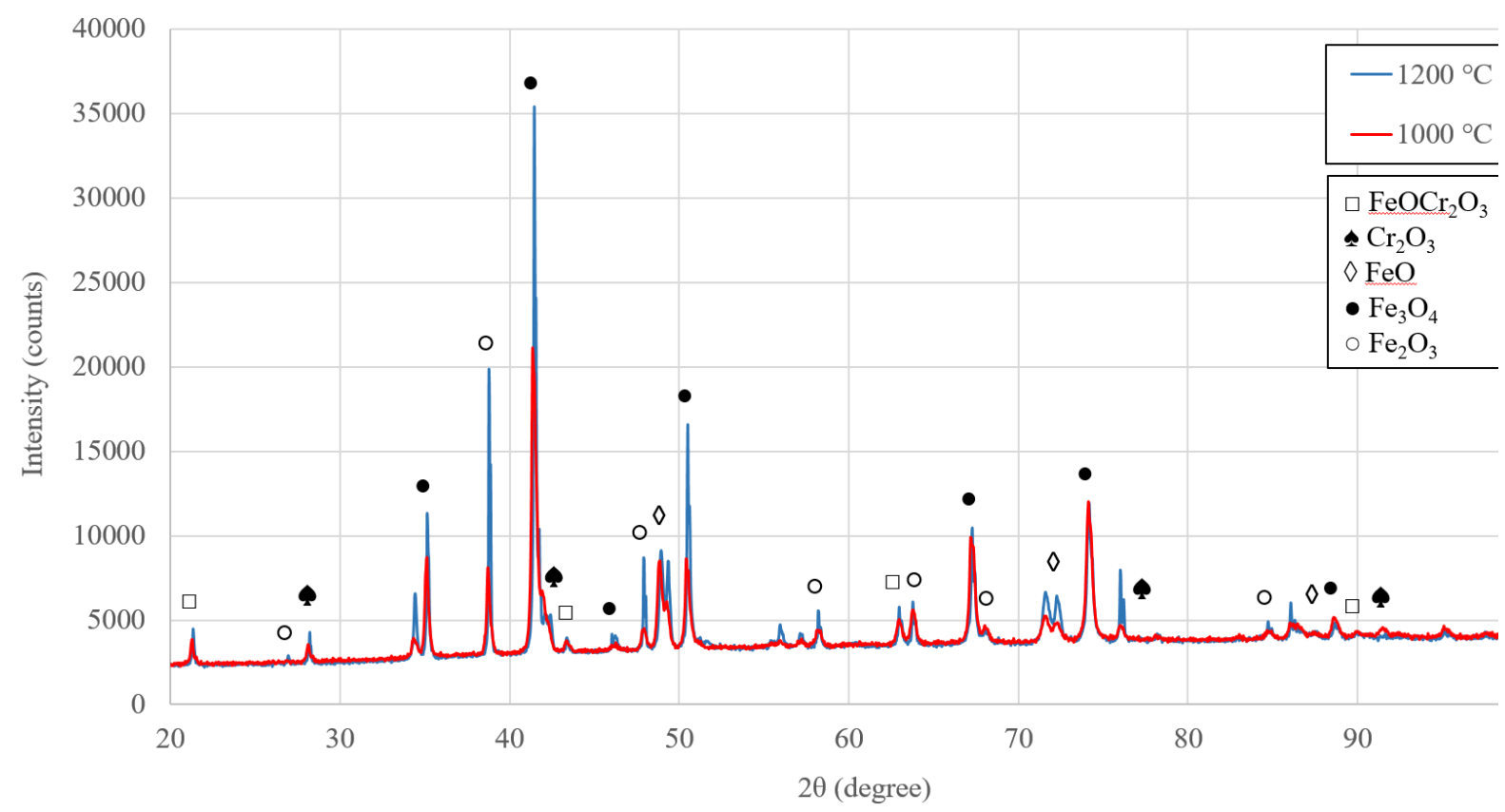

(a)

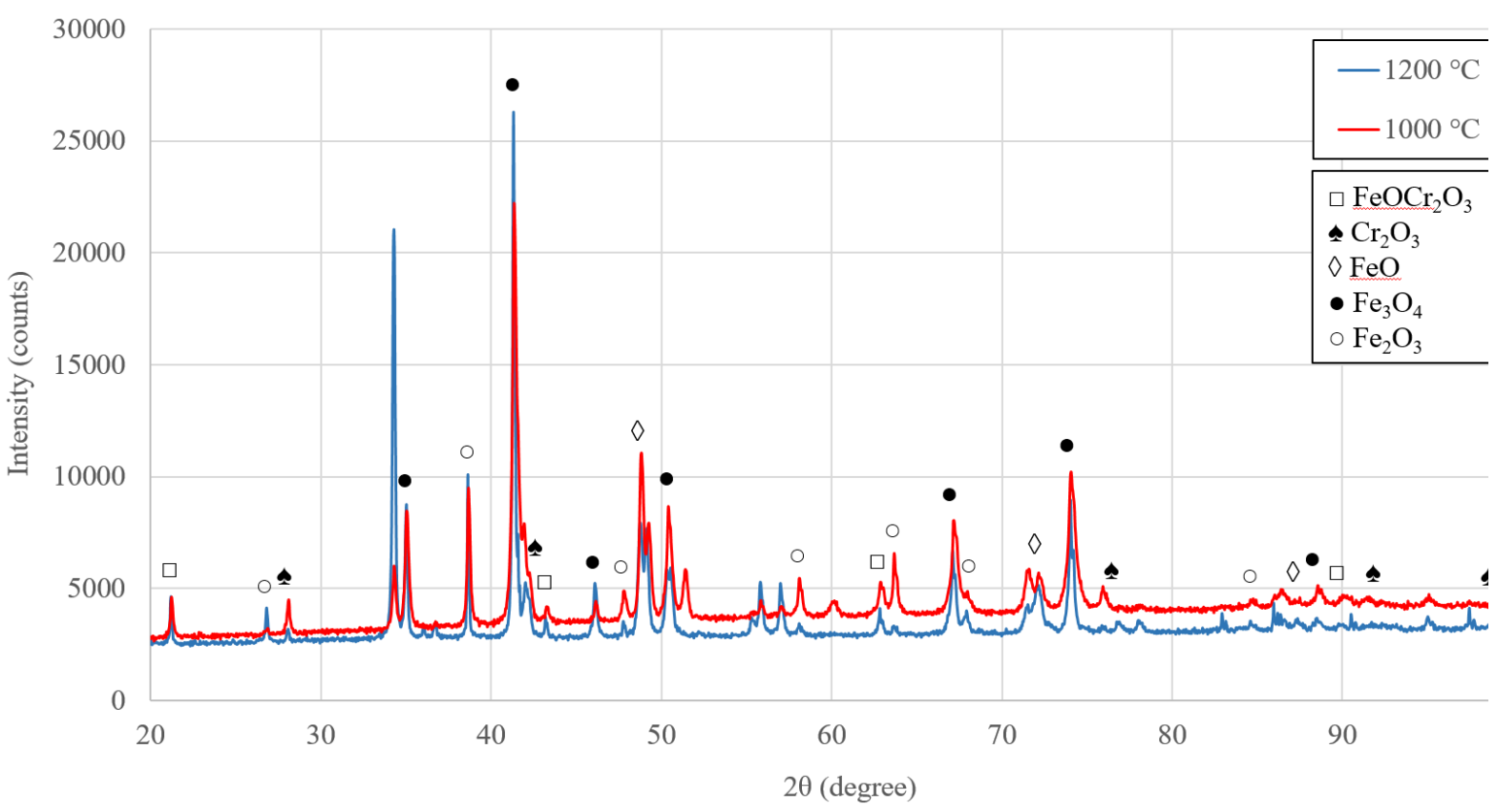

(b)

Fig. 7 XRD analysis of HNi steel oxide powder for oxidation time intervals of: a) 10 and b) $60 \mathrm{~min}$ 

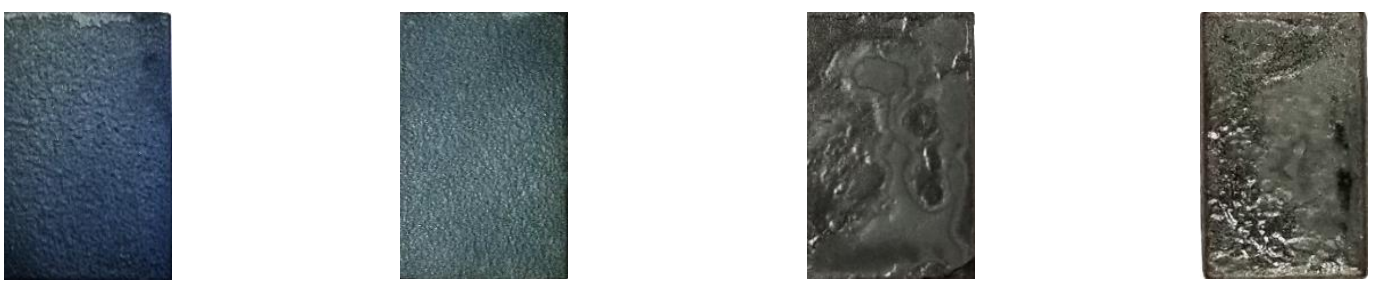

$10 \mathrm{~mm}$

$1000{ }^{\circ} \mathrm{C}-10 \mathrm{~min}$

Fig. 8 Surfaces of $\mathrm{HNi}$ samples oxidized at $1000^{\circ} \mathrm{C}$ and $1200{ }^{\circ} \mathrm{C}$ for 10 and $60 \mathrm{~min}$ 

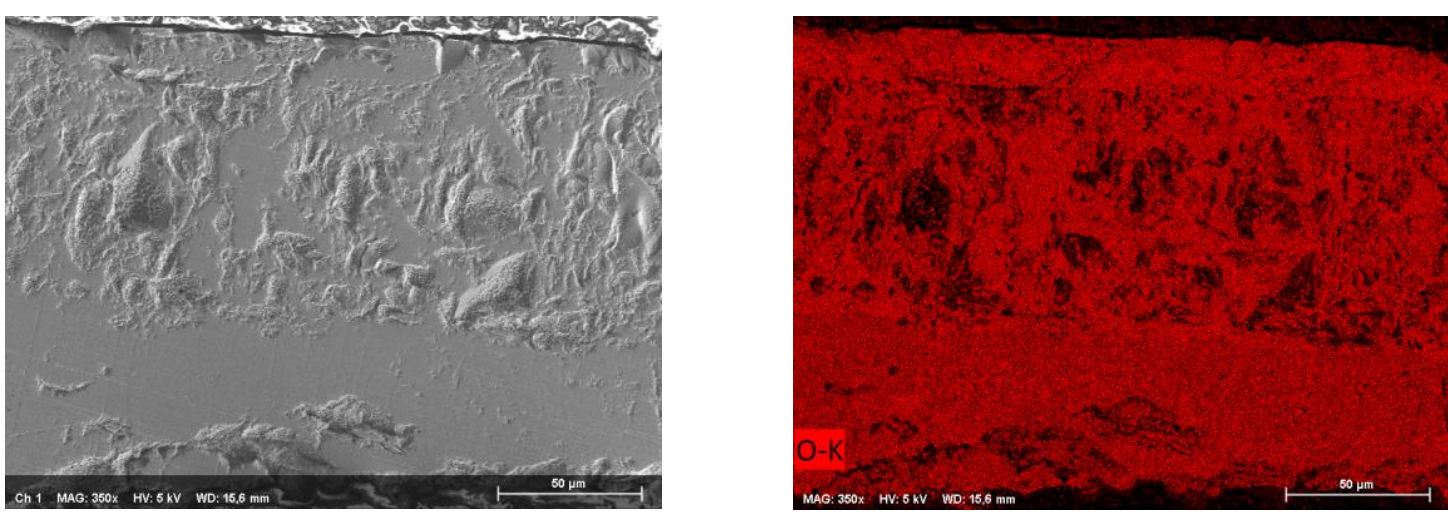

(a)
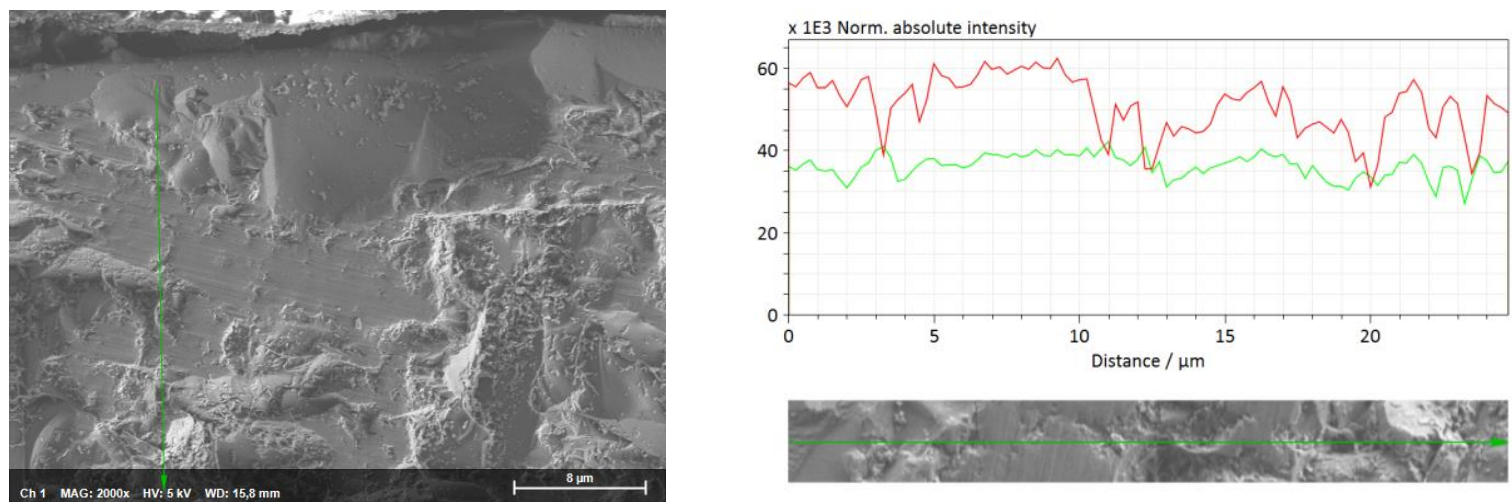

(b)

Fig. $9 \mathrm{HNi}$ steel, oxidized at $1200{ }^{\circ} \mathrm{C}$ for $10 \mathrm{~min}$ : a) oxygen elemental map, and b) oxygen line analysis (red line), (green line is the variation of Fe element) 

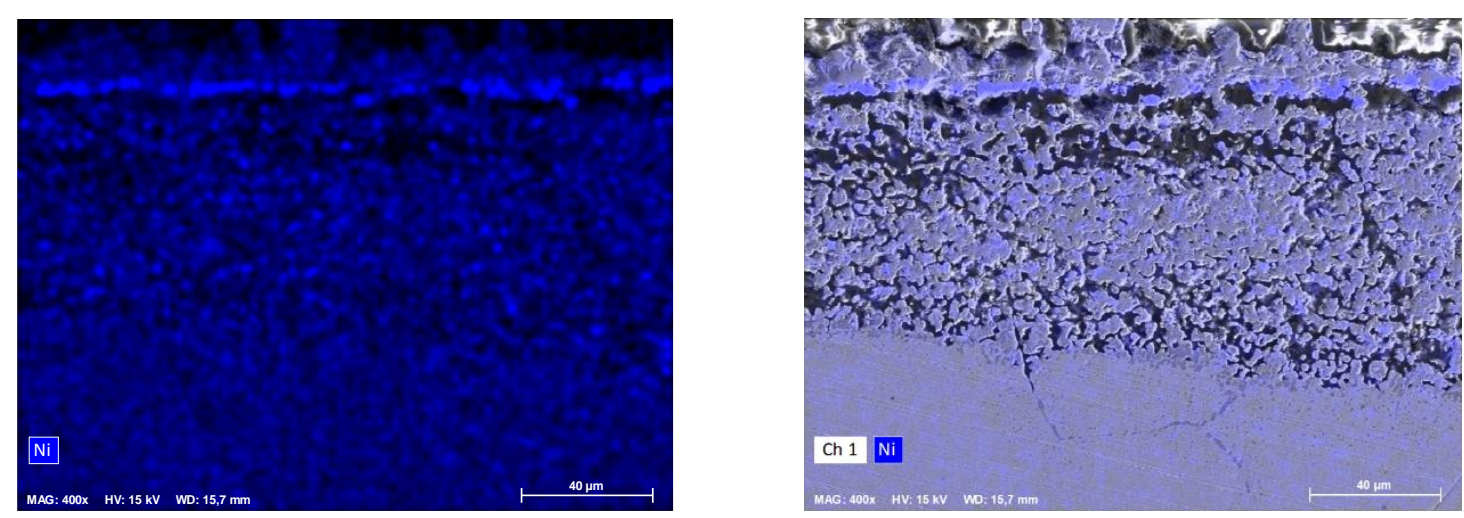

(a)
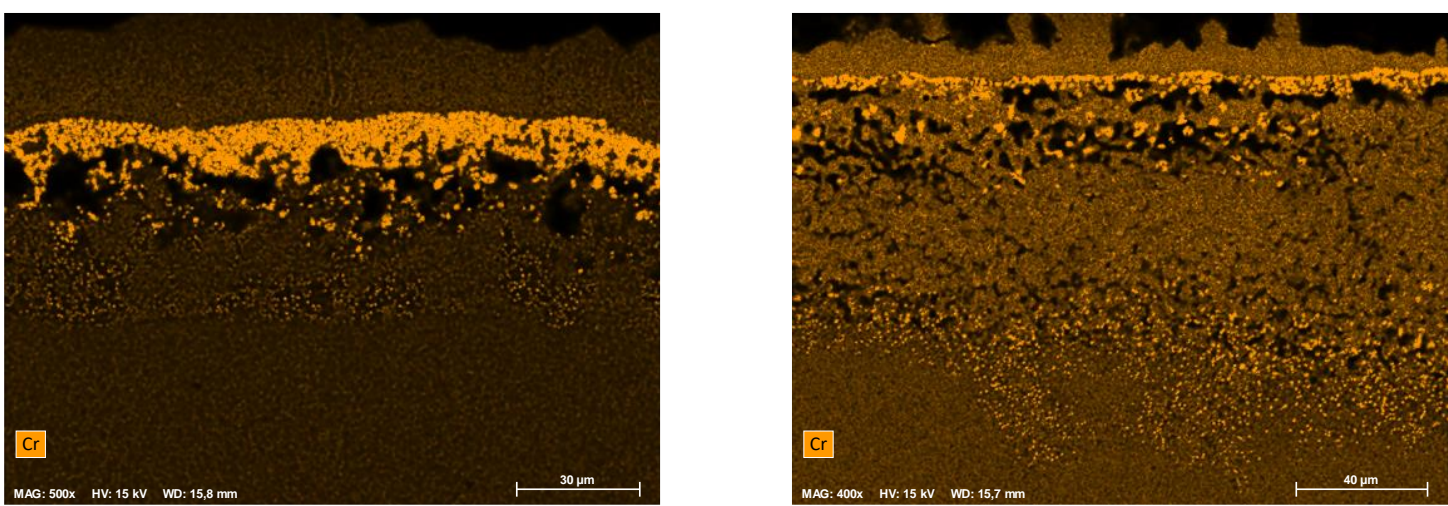

(b)

Fig. 10 Oxidized at $1200^{\circ} \mathrm{C}$ for $10 \mathrm{~min}$ : a) $\mathrm{Ni}$ elemental map for $\mathrm{HNi}$, and b) $\mathrm{Cr}$ elemental map for LNi (left) and $\mathrm{HNi}$ (right) 

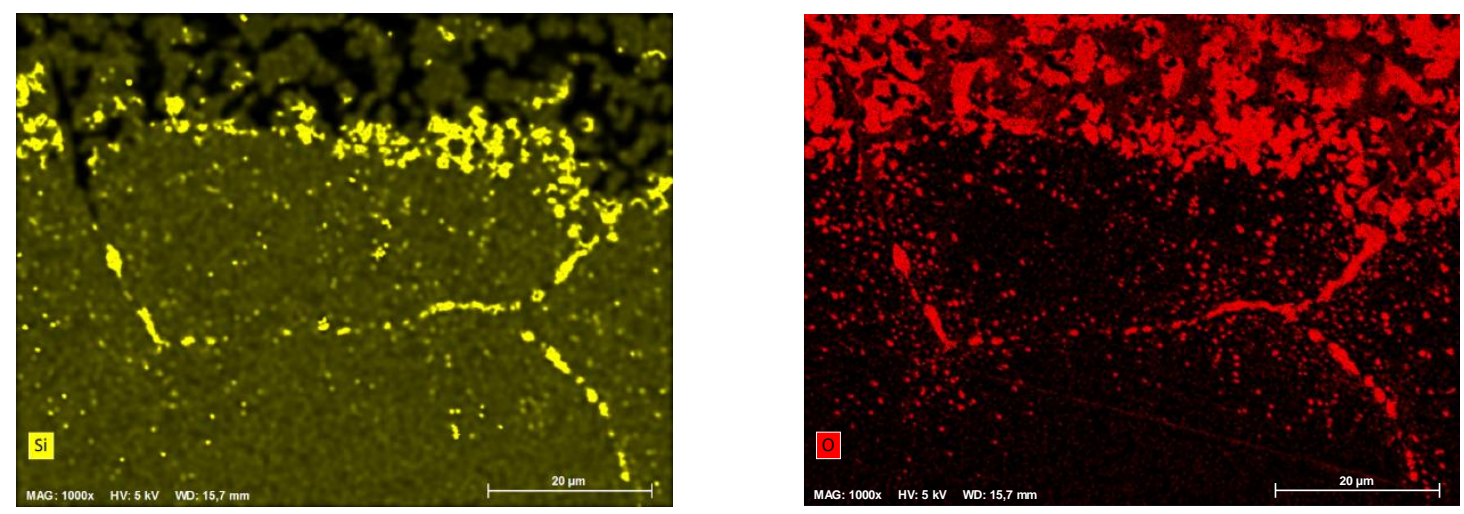

Fig. 11 The network of particles made from oxygen and $\mathrm{Si}$ in grain boundaries of HNi steel, oxidized at $1200{ }^{\circ} \mathrm{C}$ for $10 \mathrm{~min}$ 

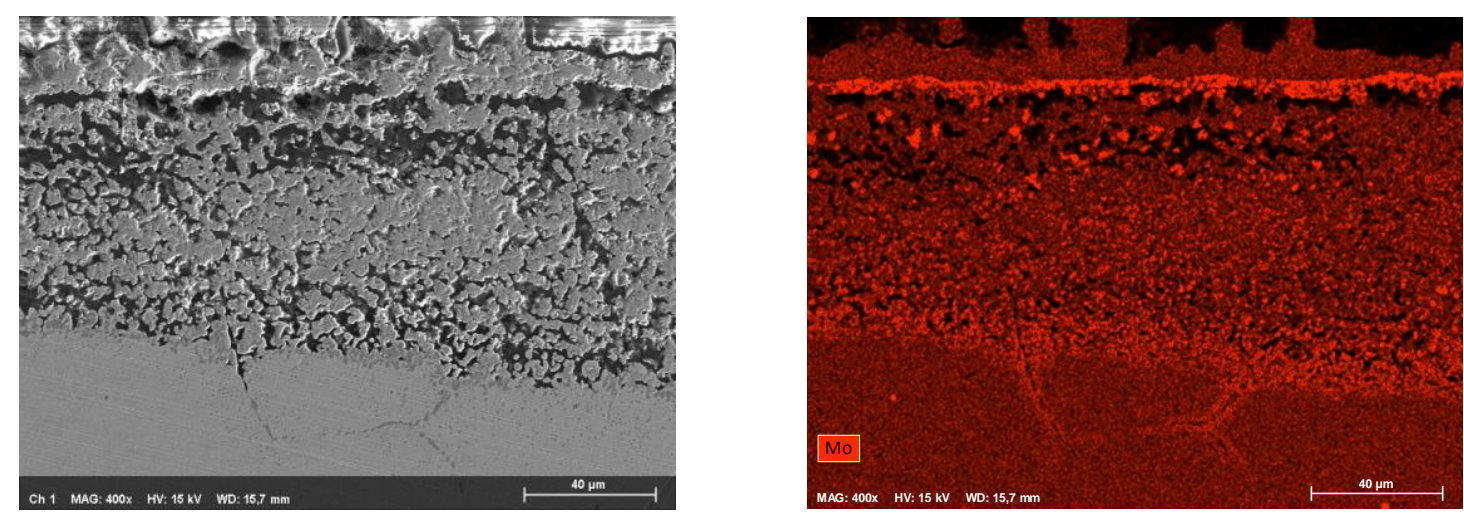

Fig. 12 Mo segregation in transition zone of oxide of HNi steel, oxidized at $1200{ }^{\circ} \mathrm{C}$ for $10 \mathrm{~min}$ 


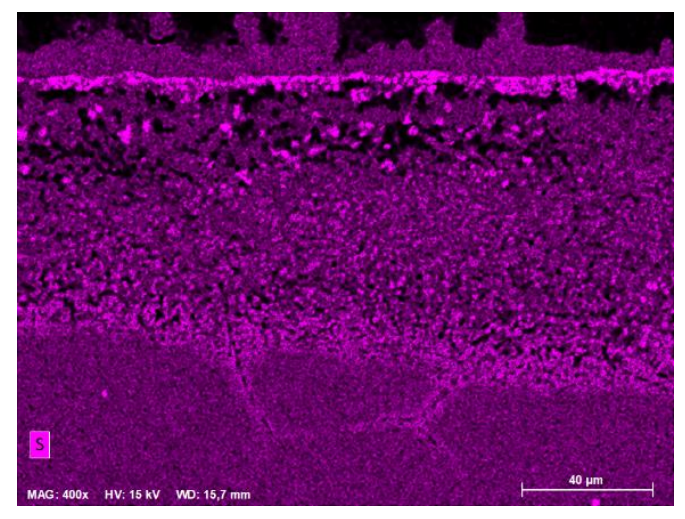

a

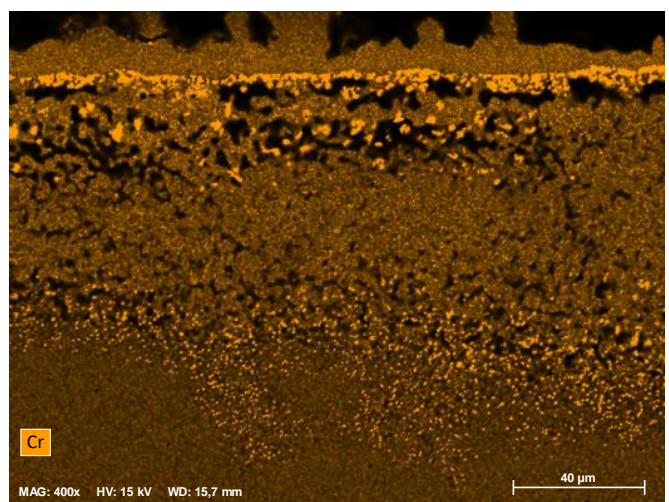

b

Fig. 13 Remained a) $\mathrm{SiO} 2$ and b) $\mathrm{Cr} 2 \mathrm{O} 3$ oxide in transition 


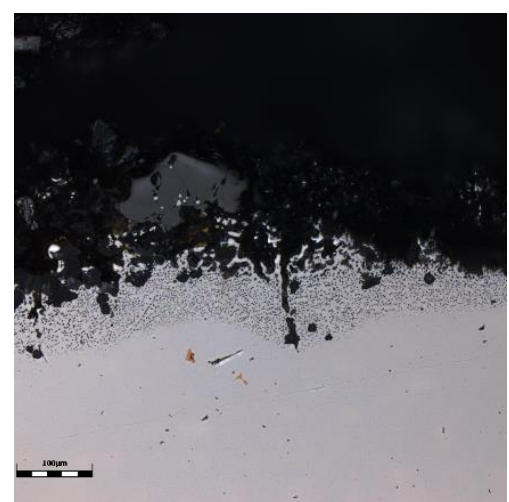

Fig. 14 Spherical shape oxides in type of wustite for $\mathrm{HNi}$ steel, oxidized at $1200{ }^{\circ} \mathrm{C}$ for $10 \mathrm{~min}$ 